\title{
Systematic Review and Meta-Analysis of Combination Therapy with Cholinesterase Inhibitors and Memantine in Alzheimer's Disease and Other Dementias
}

\author{
Taim Muayqil $^{\mathrm{a}}$ Richard Camicioli ${ }^{\mathrm{b}}$ \\ ${ }^{a}$ Division of Neurology, King Saud University, Riyadh, Saudi Arabia; ${ }^{b}$ Division of Neurology, \\ University of Alberta, Edmonton, Alb., Canada
}

\section{Key Words}

Dementia $\cdot$ Alzheimer $\cdot$ Dementia therapy $\cdot$ Combination treatment $\cdot$ Cholinesterase

inhibitors $\cdot$ Memantine $\cdot$ Side effects

\begin{abstract}
Background: $N$-methyl-D-aspartic acid antagonists (memantine) and cholinesterase inhibitors (ChEls) are the only two approved classes of drugs to treat dementia; this paper explores the evidence for using these two treatments in combination. Objective: To determine the efficacy and safety of using combination therapy with memantine and a ChEl to treat dementia in comparison to monotherapy with either memantine or a ChEl. Methods: In March 2012, we systematically searched MEDLINE/PubMed, EMBASE, Cochrane library, and grey literature databases. All study types were included, except for case series or reports, which looked at combination therapy versus monotherapy in various dementing disorders. Data was pooled for blinded randomized controlled trials (RCTs) only; mean differences and standardized mean differences were used to determine effect sizes. Results: Thirteen studies were included in this review; 3 were blinded RCTs, with a total of 971 Alzheimer's disease (AD) patients, which were included into the meta-analysis. No papers were found that primarily addressed combination therapy in other dementias. In the meta-analysis, small but statistically significant effect sizes were seen in favor of combination therapy among patients with moderate to severe AD on the scales of cognition (0.45-0.52; $p<0.0001)$, scales of functional outcomes $(0.23-0.3 ; p<0.01)$, and the neuropsychiatric inventory (3.7-4.4; $p<0.0001)$. Among the open-label studies, 3 out of 6 suggested benefits, as did the 4 included cohort studies. However, the high risk of bias encountered in the
\end{abstract}


latter two study designs limits deducing any conclusions about benefit. Conclusion: Although there were statistically significant changes in favor of combination therapy in moderate to severe $A D$, heterogeneity in scales and patient characteristics exists. However, it is unclear if clinically significant outcomes can be achieved using the combination therapy. More studies are required before a recommendation for combination therapy can be made.

Copyright $\odot 2012$ S. Karger AG, Basel

\section{Background}

Dementia is a worldwide problem that is growing in prevalence as life expectancy is increasing. In Canada, approximately 500,000 individuals have dementia today, and by 2038 , the incidence of new cases is expected to increase by 2.5 times and the prevalence by 2.3 times [1]. Wimo and Winblad [2] and Wimo et al. [3] found that the worldwide economic burden caused by dementia for both direct and indirect care was estimated to be 315.4 billion USD in 2005 , an increase from 250 billion in 2003. In the most recent study by Wimo et al. [4], the worldwide cost in 2009 was estimated to be 422 billion after considering inflation and the increase of patients with dementia.

Impairments in cognition and in activities of daily living (ADL) resulting from dementia are associated with lower quality of life in elderly patients [5]. Current available therapies for dementia provide benefits that can be considered small; a large trial found improvement of 0.8 points/year on the Mini-Mental State Examination (MMSE) in patients on donepezil in comparison to placebo [6]. Thus, there is a growing literature of studies aimed at discovering new treatments.

Pharmacological interventions that have been found to impact cognition include drugs with cholinesterase inhibitory action that help increase the levels of the deficient neurotransmitter, acetylcholine. The main cholinesterase inhibitors (ChEIs) in use are donepezil, galantamine and rivastigmine. These drugs are currently approved for use in patients with mild to moderate Alzheimer's disease (AD), except for rivastigmine, which is approved for Parkinson's disease dementia, and donepezil, which also has approval for use in severe AD in the United States. Donepezil was favored by caregivers in one study over other ChEIs particularly due to its ease of use [7]. In addition to improvements and stabilization in cognitive and functional measures, there may be less clinical worsening while on donepezil [8].

The activation of $N$-methyl-D-aspartic acid (NMDA) receptors found on neurons by toxic neurotransmitters is believed to mediate neuronal death [9], contributing to the development of dementia. Memantine, which is currently the only drug in clinical use for dementia that has NMDA antagonistic activity, is approved for administration to patients with moderate to severe AD. A review found that memantine was superior to placebo in controlling behavioral symptoms [10]. Another paper that looked at the data of 6 randomized, double-blind, placebo-controlled studies concluded that patients on placebo were more likely to exhibit worsening in either cognitive or functional measures [11]. Current approval for both classes of drugs is restricted to patients with $\mathrm{AD}$. However, off-label use is increasing in the form of extending the administration of these drugs to other types of dementia and/or using them in combination. Emerging studies have reported positive responses to combination therapy in aspects of both patient behavior and cognition $[12,13]$. The available literature suggests a favorable adverse effect profile to the combination as well [14]. Combination therapy has been considered potentially beneficial as dementia involves multiple pathological processes and not just a cholinergic deficit [15]. Since physicians are using ChEIs off-label in non-AD dementia and evidence for memantine is emerging [16], combination therapy for non-AD dementia patients is a possibility requiring consideration. 
Muayqil et al.: Systematic Review and Meta-Analysis of Combination Therapy with

Cholinesterase Inhibitors and Memantine in Alzheimer's Disease and Other Dementias

Little can actually be done apart from supportive care for most patients with dementia. If the use of combination therapy could help maintain a patient independent longer or reduce the requirement of supportive care for a significant period, then this would have a significant impact both financially and socially. A cost-effectiveness study of combination therapy with memantine and donepezil in patients with moderate to severe AD showed that, despite the increase in cost from additional drug therapy, there was a net decrease in the cost of total lifetime AD-related care [17]. This adds support for the need to investigate the usefulness of combination therapy in dementia.

The objective of this systematic review is to determine the efficacy and safety of the use of combination therapy (ChEI and memantine) in treating patients with cognitive impairment or dementia of degenerative or vascular origin.

\section{Methods}

\section{Study Eligibility}

The systematic review protocol was determined a priori. The studies included were English language blinded and/or open-label randomized controlled trials (RCTs), quasi-RCTs, non-RCTs, cohort and case control studies. Non-RCTs were included given the anticipated paucity of RCTs in the area. Included studies were performed on community-living adults $>18$ years of age with a diagnosis of a degenerative or vascular dementia that was determined by the diagnostic clinical criteria and tools used by the authors. These studies were to compare the use of the combination of a ChEI with memantine (experimental group) with either memantine monotherapy or ChEI monotherapy (control group). This included any route of administration, at any dose for any duration of treatment. Dementias due to conditions such as metabolic, traumatic, inflammatory, drug or malignant processes were excluded. Vascular dementia was included because it is a disease of elderly that can have a slowly progressive course with a cholinergic deficit similar to that seen in the pathophysiological process of other degenerative dementias. Additionally, it often coexists with dementia of other causes, such as $\mathrm{AD}$, creating a 'mixed dementia'. The primary outcomes assessed were the changes in measures of cognitive ability and functional ability by the scale used by the authors. Secondary outcome measures assessed were clinical global impression, institutionalization rates (of community-dwelling patients), behavioral changes, quality of life, and death rates. All of the outcomes were determined using the scales from each study. Patient report was accepted when assessing for side effects. Side effects were the events each study considered to be an adverse outcome. The side effects were categorized as follows: 'dizziness and nausea', 'gastrointestinal', 'balance difficulty, fall or injury', 'urinary symptoms', 'neurobehavioral symptoms', 'upper respiratory tract infection, flu-like symptoms or fatigue', 'headache', 'institutionalization', 'death', and 'other'. Dropouts were determined by looking at the withdrawal rate of patients from each study.

\section{Information Sources}

The electronic databases of MEDLINE, PubMed, Cochrane Library, and EMBASE were searched from the dates of their inception to February 2011; the search was repeated in March 2012 when a new relevant paper was published. In addition, the reference lists of the articles identified and of review papers were hand searched to identify articles not found by the search engine. Other sources searched were conference proceedings, abstracts, thesis dissertations, grey literature journals, clinicaltrials.gov, and the Controlled Clinical Trials Search databases. Reviews without original data, meeting abstracts, and case reports/series were excluded. Search terms included cognitive decline or impairment, dementia, ChEIs (as 
a group), donepezil, galantamine, rivastigmine, tacrine (individual ChEIs), and memantine (the only drug in its class). The drugs' corresponding most commonly used trade names were also used. The ChEI terms were combined with memantine and the disease terms (appendix 1). Clinicaltrials.gov was also searched in an attempt to find any trials that might have been missed, and an effort was made to contact the authors of ongoing trials for further information on 'in-press' data where appropriate.

\section{Screening}

After the articles were obtained from the initial search, the first level of screening was performed by one of the authors (T.M.) after inspecting the abstracts and titles. Irrelevant publications or duplications were discarded at this stage. At the second level of screening, the papers were assessed by both authors (T.M. and R.C.) for information relating to the type of participants, type and dose of medicinal product used, and duration of follow-up. A worksheet that contained criteria for inclusion and exclusion was used to select the appropriate articles. Disagreements were resolved by consensus, and a record was kept of excluded articles.

\section{Quality Assessment}

The Cochrane risk of bias tool [18] was used for assessing bias in RCTs, and the Newcastle-Ottawa scale [19] was used for assessing bias risk for cohort studies and case-control studies. Further information about methodological quality was obtained by extracting details of the trial design, randomization, allocation and concealment methods, the number of patients excluded or lost to follow-up, and the outcome measures stated in the protocol.

\section{Data Extraction}

Data extraction was carried out by T.M. and verified by R.C. The information extracted included the demographic information of patients, diagnosis, drugs used (from both intervention and control groups), the response to the drugs used and the safety profile of the drugs, and the changes in patient outcome measures from their baseline performance that was determined at the start of each study. For studies with dichotomous variables (i.e. side effects), the number in each group experiencing the outcome of interest was determined. Disagreements were resolved by consensus.

\section{Data Analysis}

When the same continuous outcome scale was used among the pooled studies in the meta-analysis, the weighted mean difference was the summary statistic used to determine effect size. When the outcome measure scale varied among the studies that were to have their results pooled, the standardized mean difference was used to determine effect size. Standard errors (SEs) or confidence intervals (CIs) were converted to standard deviations (SDs) when required. Random effects models were used to combine results. $\mathrm{I}^{2}$ test was used to test for heterogeneity, which was determined significant at $50 \%$. A funnel plot was to be used if there were an appropriate number of articles. With regard to dichotomous variables, the odds ratio was used to measure the effect. Revman 5 software was used to process the results.

Sensitivity analysis comparing the results of blinded RCTs, when more than one scale was used to assess a single outcome, was conducted. Subgroup analysis was to be performed if there was adequate literature assessing response to different dementing disorders, or by different type of ChEI used. 


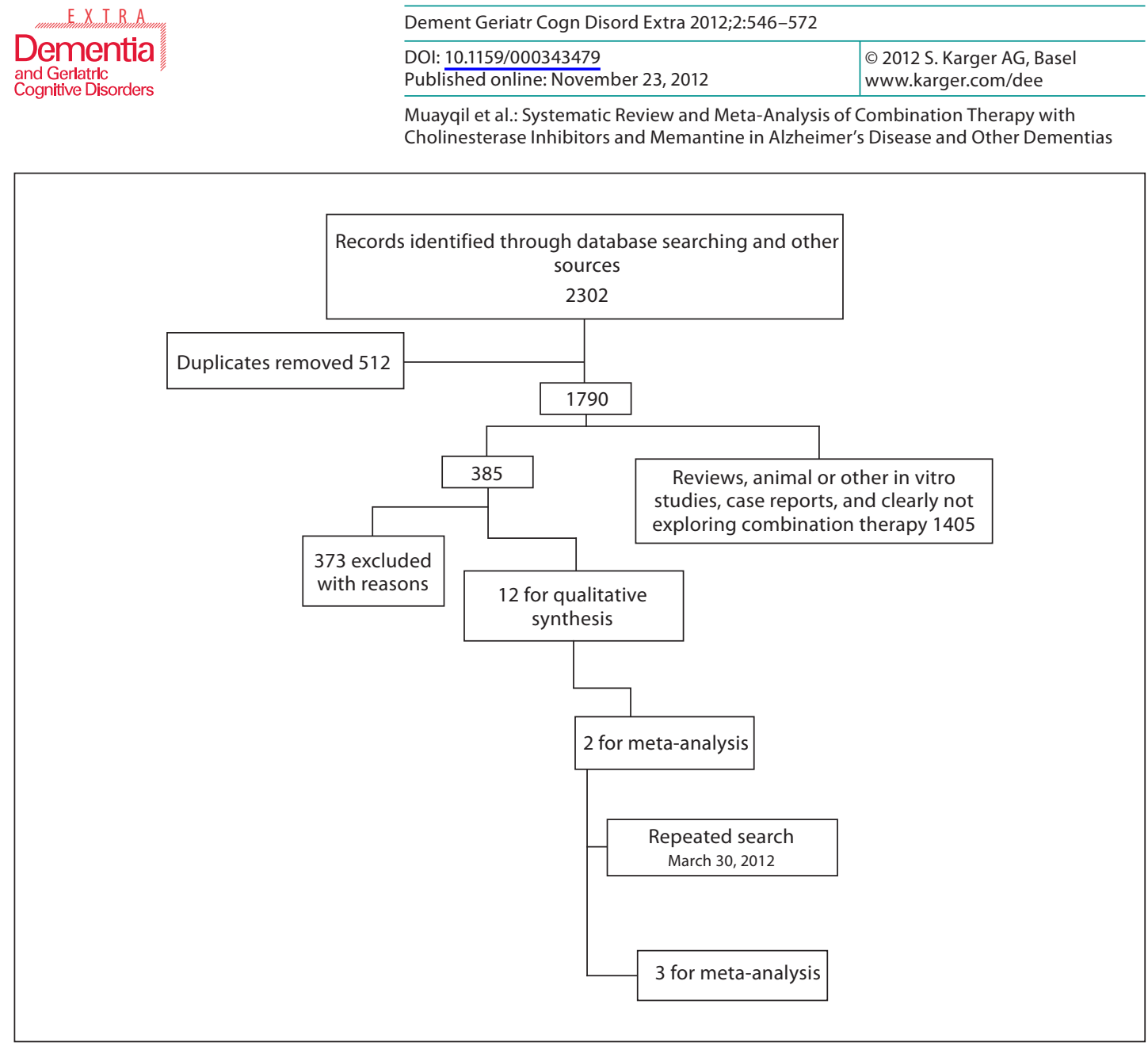

Fig. 1. Flow chart of the results of the search process.

\section{Results}

The results of the search process are depicted in the flow chart (fig. 1). Thirteen studies were included in this review (table 1). The search yielded 3 blinded RCTs (Tariot et al. [13], Porsteinsson et al. [20], and Howard et al. [21]; table 2), 2 open-label RCTs (Farlow et al. [22] and Choi et al. [23]; table 3), 4 open-label non-RCT experimental studies (Dantoine et al. [14], Riepe et al. [24], Olin et al. [25], and Shua-Haim et al. [26]; table 3), and 4 cohort studies (Schneider et al. [27], Lopez et al. [28], Hartmann and Mobius [29], and Atri et al. [12]; table 4). Only the results of the blinded RCTs will be discussed in detail, and information regarding the remaining studies can be obtained in tables 2-4 and appendix 2; a list of excluded studies can be obtained from the authors.

With the exception of the Donepezil and Memantine in Moderate to Severe Alzheimer's Disease (DOMINO) trial by Howard et al. [21], all of the studies compared patients on ChEI monotherapy with patients on ChEI and memantine in the combination therapy arm. Only the DOMINO trial had a memantine monotherapy arm. AD was the only dementia syndrome that was studied. Only 1 study looked at institutionalization rates (Lopez et al. [28]), and only the DOMINO trial performed a quality of life assessment. There was little detail regarding factors that are known to be associated with dementia such as diabetes, hypertension, and $\mathrm{APOE} \varepsilon 4$ status. A sensitivity analysis considering these associations could thus not be performed. Due to heterogeneity of the methods, the results of trials other than the blinded RCTs were not meta-analyzed. 
Muayqil et al.: Systematic Review and Meta-Analysis of Combination Therapy with

Cholinesterase Inhibitors and Memantine in Alzheimer's Disease and Other Dementias

Table 1. The studies' main finding in relation to the severity of $\mathrm{AD}$ and its likelihood for bias

\begin{tabular}{|c|c|c|c|c|}
\hline $\begin{array}{l}\text { Type of } \\
\text { study }\end{array}$ & $\begin{array}{l}\text { Study } \\
\text { authors }\end{array}$ & Main results & Disease severity & $\begin{array}{l}\text { Bias risk } \\
\text { assessment }\end{array}$ \\
\hline \multirow[t]{3}{*}{$\begin{array}{l}\text { Blinded } \\
\text { RCTs }\end{array}$} & Tariot et al. [13], 2004 & $\begin{array}{l}\text { statistically significant difference in favor of } \\
\text { combination therapy for cognition and } \\
\text { function }\end{array}$ & moderate to severe & $\begin{array}{l}\text { undetermined } \\
\text { (ROB) }\end{array}$ \\
\hline & $\begin{array}{l}\text { Porsteinsson et al. [20], } \\
2008\end{array}$ & $\begin{array}{l}\text { no statistically significant difference between } \\
\text { groups }\end{array}$ & mild to moderate & $\begin{array}{l}\text { undetermined } \\
\text { (ROB) }\end{array}$ \\
\hline & Howard et al. [21], 2012 & $\begin{array}{l}\text { for patients previously taking donepezil: } \\
\text { continuation with donepezil was significantly } \\
\text { better than placebo; continuation with } \\
\text { memantine was significantly better than } \\
\text { placebo; the interaction of donepezil with } \\
\text { memantine was not significant }\end{array}$ & moderate to severe & low (ROB) \\
\hline \multirow{6}{*}{$\begin{array}{l}\text { Open- } \\
\text { label } \\
\text { trials }\end{array}$} & Dantoine et al. [14], 2006 & $\begin{array}{l}\text { improvement in behavior, cognition, and } \\
\text { function in favor of combination therapy }\end{array}$ & moderate to severe & high (ROB) \\
\hline & Riepe et al. [24], 2007 & $\begin{array}{l}\text { tolerable and statistically significant } \\
\text { improvement in cognition in favor of } \\
\text { combination therapy }\end{array}$ & $\begin{array}{l}\text { mild to moderate } \\
\text { (more impaired appeared } \\
\text { to benefit more) }\end{array}$ & high (ROB) \\
\hline & Olin et al. [25], 2010 & $\begin{array}{l}\text { combination therapy is tolerable and safe, and } \\
\text { associated with modest changes in cognition } \\
\text { and function }\end{array}$ & moderate & high (ROB) \\
\hline & Shua-Haim et al. [26], 2008 & combination considered well tolerated & mild to moderate & high (ROB) \\
\hline & Farlow et al. [22], 2010 & no significant difference & mild to moderate & high (ROB) \\
\hline & Choi et al. [23], 2011 & no significant difference (except in CMAI-K) & moderate & high (ROB) \\
\hline \multirow[t]{4}{*}{$\begin{array}{l}\text { Cohort } \\
\text { studies }\end{array}$} & $\begin{array}{l}\text { Hartmann } \\
\text { and Mobius [29], } 2003\end{array}$ & in favor of combination & not reported & 1 star (NOS) \\
\hline & Atri et al. [12], 2008 & $\begin{array}{l}\text { statistically significant difference in favor of } \\
\text { combination therapy for cognition and function }\end{array}$ & varying severity & 6 stars (NOS) \\
\hline & Lopez et al. [28], 2009 & statistically significant fewer $\mathrm{NH}$ admissions & $\begin{array}{l}\text { not reported, but } \\
\text { mean MMSE } 17.4 \pm 5.6\end{array}$ & 7 stars (NOS) \\
\hline & Schneider et al. [27], 2011 & $\begin{array}{l}\text { statistically significant difference in favor of } \\
\text { monotherapy for cognition and function }\end{array}$ & mild $\mathrm{AD}$ & 7 stars (NOS) \\
\hline
\end{tabular}

ROB = Cochrane risk of bias tool; NOS = Newcastle-Ottawa scale (smaller values correspond to higher risks of bias); CMAI-K = Korean version of the Cohen-Mansfield Agitation Inventory; $\mathrm{NH}=$ nursing home.

Comorbidities of patients were provided by some of the studies. In the study by Tariot et al. [13], frequent medical conditions were not specifically mentioned; however, the neurological and cardiovascular systems were involved in at least 34 and $20 \%$ of each treatment arm. Schneider et al. [27] observed that there were more carriers of APOE $\varepsilon 4$ in the ChEIonly group (74.4 vs. 58.9\%). In the study by Lopez et al. [28], hypertension and heart disease were less prevalent in the no-medication group, and the occurrence of diabetes and APOE $\varepsilon 4$ status was similar among the groups. Circulatory and nervous system disorders were the most concomitant conditions in the population from Hartmann and Mobius [29]. Dantoine et al. [14] found most prevalent comorbidities to be vascular (48.8\%) and metabolic disorders (28.4\%).

\section{Blinded RCTs}

The Tariot et al. [13] study included 37 centers in the US with an intended patient observation period of 24 weeks per person. Their target population was those who had moderate to severe probable AD by NINCDS-ADRDA criteria and an MMSE score ranging from 5 to 14 , and on a stable dose of donepezil for the 3 months prior to the study. A total 
Table 2. Characteristics of blinded RCTs

\begin{tabular}{|c|c|c|c|c|}
\hline & Tariot et al. [13], 2004 & Porsteinsson et al. [20], 2008 & \multicolumn{2}{|l|}{ Howard et al. [21], 2012} \\
\hline \multicolumn{5}{|c|}{ Randomized patients, $n$} \\
\hline Placebo & 201 & 216 & \multicolumn{2}{|r|}{76 (memantine) } \\
\hline Treatment & 203 & 217 & \multicolumn{2}{|l|}{73} \\
\hline \multicolumn{5}{|l|}{ Age, years } \\
\hline Placebo & $75.5 \pm 8.73 \mathrm{SD}$ & $76.0 \pm 8.43 \mathrm{SD}$ & $77.2 \pm 7.5 \mathrm{SD}$ (donepezil) & $\begin{array}{l}76.2 \pm 8.9 \mathrm{SD} \\
\text { (memantine) }\end{array}$ \\
\hline Treatment & $75.5 \pm 8.45 \mathrm{SD}$ & $74.9 \pm 7.64 \mathrm{SD}$ & \multicolumn{2}{|l|}{$77.5 \pm 9.0 \mathrm{SD}$} \\
\hline \multicolumn{5}{|c|}{ Females, $n(\%)$} \\
\hline Placebo & $134(67)$ & $109(50.5)$ & \multirow{2}{*}{\multicolumn{2}{|c|}{$\begin{array}{l}51(70) \text { (donepezil) } \\
49(67)\end{array}$}} \\
\hline Treatment & $128(63)$ & $117(53.9)$ & & \\
\hline \multicolumn{5}{|c|}{ Completion rate, $n(\%)$} \\
\hline Placebo & $150(74.6)$ & $191(88.4)$ & \multicolumn{2}{|l|}{54 (74) (donepezil) } \\
\hline Treatment & $172(85.1)$ & $194(89.4)$ & \multicolumn{2}{|l|}{$58(79.5)$} \\
\hline \multicolumn{5}{|c|}{ Monotherapy drug dose, mg/patients, $n(\%)$} \\
\hline Placebo & donepezil $9.49 \pm 1.88 \mathrm{SD}$ & $\begin{array}{l}\text { donepezil } 8.9 \pm 2.1 \mathrm{SD} / 137(63.4) \\
\text { rivastigmine } 10.0 \pm 2.6 \mathrm{SD} / 44(20.4) \\
\text { galantamine } 19.4 \pm 5.2 \mathrm{SD} / 35(16.2)\end{array}$ & 10 mg/day (donepezil) & $\begin{array}{l}20 \mathrm{mg} / \text { day } \\
\text { (memantine) }\end{array}$ \\
\hline Treatment & donepezil $9.25 \pm 1.79$ SD & $\begin{array}{l}\text { donepezil } 9.5 \pm 1.5 \mathrm{SD} / 154(71.0) \\
\text { rivastigmine } 9.2 \pm 2.8 \mathrm{SD} / 33(15.2) \\
\text { galantamine, } 19.7 \pm 4.6 \mathrm{SD} / 30(13.8)\end{array}$ & 10 mg/day (donepezil) & $\begin{array}{l}20 \text { mg/day } \\
\text { (memantine) }\end{array}$ \\
\hline \multicolumn{5}{|c|}{ MMSE score at baseline } \\
\hline Placebo & $10.2 \pm 2.98 \mathrm{SD}$ & $17.0 \pm 3.64 \mathrm{SD}$ & $9.0 \pm 2.8 \mathrm{SD}$ (donepezil) & $\begin{array}{l}9.2 \pm 2.5 \mathrm{SD} \\
\text { (memantine) }\end{array}$ \\
\hline Treatment & $9.9 \pm 3.13 \mathrm{SD}$ & $16.7 \pm 3.67 \mathrm{SD}$ & \multicolumn{2}{|l|}{$9.1 \pm 2.6 \mathrm{SD}$} \\
\hline \multicolumn{5}{|c|}{ Other cognitive tests at baseline } \\
\hline Placebo & SIB $80.0 \pm 1.13 \mathrm{SE}$ & ADAS- $\operatorname{cog} 26.8 \pm 9.88$ SD & \multicolumn{2}{|l|}{-} \\
\hline Treatment & SIB $78.0 \pm 1.11 \mathrm{SE}$ & ADAS- $\operatorname{cog} 27.9 \pm 10.98 \mathrm{SD}$ & \multicolumn{2}{|l|}{-} \\
\hline \multicolumn{5}{|l|}{ Outcome } \\
\hline Placebo & $\begin{array}{l}\text { SIB change from baseline } \\
-2.5 \pm 0.69 \text { SE; } \\
\text { MMSE not reported }\end{array}$ & $\begin{array}{l}\text { ADAS-cog } 28.0 \pm 11.94 \text { SD } \\
\text { MMSE } 16.4 \pm 5.08 \text { SD }\end{array}$ & \multirow{2}{*}{\multicolumn{2}{|c|}{$\begin{array}{l}\text { MMSE average difference donepezil + memantine vs. } \\
\text { donepezil 0.8 }(95 \% \text { CI }-0.1 \text { to } 1.6) \text {; MMSE average } \\
\text { difference donepezil + memantine vs. memantine } \\
1.5(95 \% \text { CI } 0.6-2.3)\end{array}$}} \\
\hline Treatment & $\begin{array}{l}\text { SIB change from baseline } \\
0.9 \pm 0.67 \mathrm{SE} \\
\text { MMSE not reported }\end{array}$ & $\begin{array}{l}\text { ADAS- } \operatorname{cog} 28.5 \pm 12.83 \mathrm{SD} \\
\text { MMSE } 16.5 \pm 5.38 \mathrm{SD}\end{array}$ & & \\
\hline \multicolumn{5}{|c|}{ Functional scale at baseline (ADCS-ADL) } \\
\hline Placebo & ADCS- $\mathrm{ADL}_{19} 35.8 \pm 0.74 \mathrm{SE}$ & $\mathrm{ADCS}_{-\mathrm{ADL}_{23}} 54.8 \pm 13.08 \mathrm{SD}$ & $\begin{array}{l}\text { BADLS } 28.2 \pm 9 \text { SD } \\
\text { (donepezil) }\end{array}$ & $\begin{array}{l}\text { BADLS 27.1 } \pm 9 \text { SD } \\
\text { (memantine) }\end{array}$ \\
\hline Treatment & ADCS-ADL ${ }_{19} 35.5 \pm 0.73 \mathrm{SE}$ & $\mathrm{ADCS} \mathrm{ADL}_{23} 54.7 \pm 14.44 \mathrm{SD}$ & \multicolumn{2}{|l|}{ BADLS $26.9 \pm 9.8 \mathrm{SD}$} \\
\hline \multicolumn{5}{|c|}{ Functional outcome (ADCS-ADL) } \\
\hline Placebo & $\begin{array}{l}\text { Change from baseline } \\
\text { ADCS-ADL }_{19}-3.4 \pm 0.51 \mathrm{SE}\end{array}$ & $\mathrm{ADCS}_{-\mathrm{ADL}_{23}} 52.0 \pm 15.70 \mathrm{SD}$ & \multirow{2}{*}{\multicolumn{2}{|c|}{$\begin{array}{l}\text { BADLS average difference donepezil + memantine vs. } \\
\text { donepezil }-0.5(95 \% \text { CI }-2.2 \text { to } 1.2) \text {; BADLS average } \\
\text { difference donepezil + memantine vs. memantine } \\
-2.0(95 \% \text { CI }-3.7 \text { to }-0.3)\end{array}$}} \\
\hline Treatment & $\begin{array}{l}\text { Change from baseline } \\
\text { ADCS-ADL } \mathrm{AD}_{19}-2.0 \pm 0.50 \mathrm{SE}\end{array}$ & $\mathrm{ADCS}_{-\mathrm{ADL}_{23}} 51.8 \pm 15.89 \mathrm{SD}$ & & \\
\hline
\end{tabular}

of 404 patients were initially randomized (201 on placebo and 203 on memantine) and the efficacy analysis was carried out on a modified intention-to-treat (ITT) population ( $\mathrm{n}=$ 395) using the Last Observation Carried Forward (LOCF) approach [the observed case (OC) approach was also used]. The MMSE score was reported at baseline and was required for patient inclusion and determining disease severity; it was not reported among the outcome measures. 
Dementia

and Geriatic
Cognitive Disorders
Dement Geriatr Cogn Disord Extra 2012;2:546-572

\begin{tabular}{l|l}
\hline DOI: $10.1159 / 000343479$ & ○ 2012 S. Karger AG, Base
\end{tabular}

Published online: November 23, 2012

www.karger.com/dee

1.: Systematic Review and Meta-Analysis of Combination Therapy w

Cholinesterase Inhibitors and Memantine in Alzheimer's Disease and Other Dementias
(1)
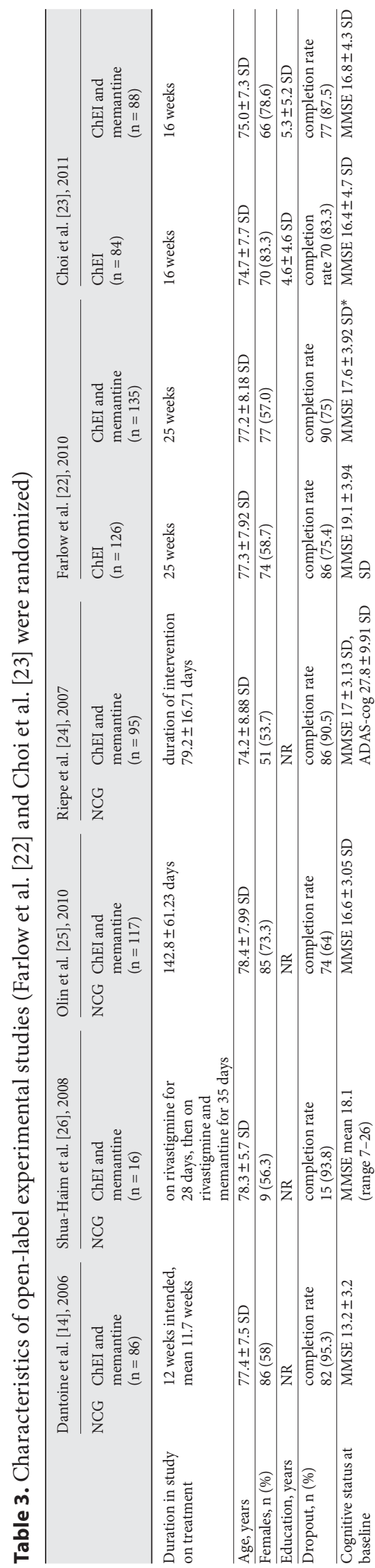

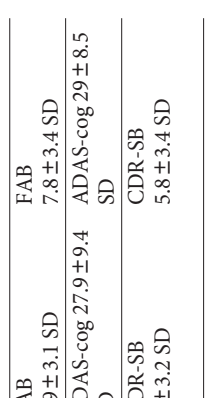

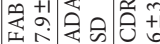

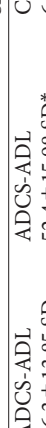

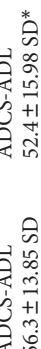

४

$\tilde{z}$

そิ

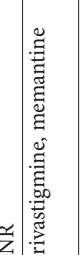

艺

艺萢

艺

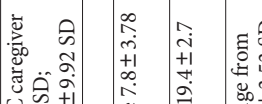

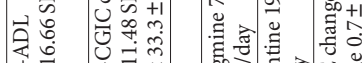

定+1

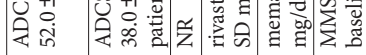

$\tilde{z}$

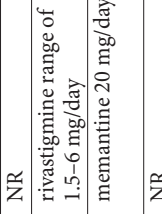

艺

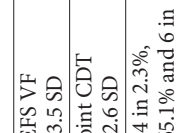

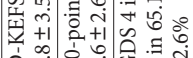

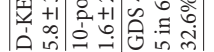

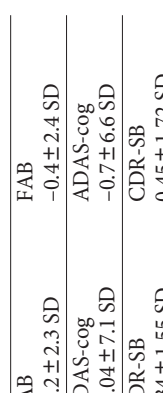

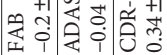

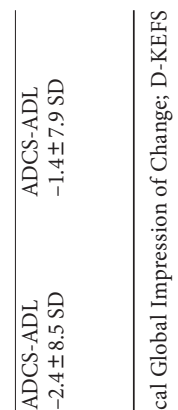

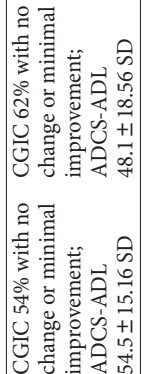

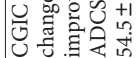


Dementia

and Geriatic
Cognitive Disorders

\begin{tabular}{l|l}
\hline \multicolumn{2}{l}{ Dement Geriatr Cogn Disord Extra 2012;2:546-572 } \\
\hline DOI: $10.1159 / 000343479$ \\
Published online: November 23, 2012 & $\begin{array}{l}\text { @ } 2012 \text { S. Karger AG, Basel } \\
\text { www.karger.com/dee }\end{array}$ \\
\hline
\end{tabular}

www.karger.com/dee

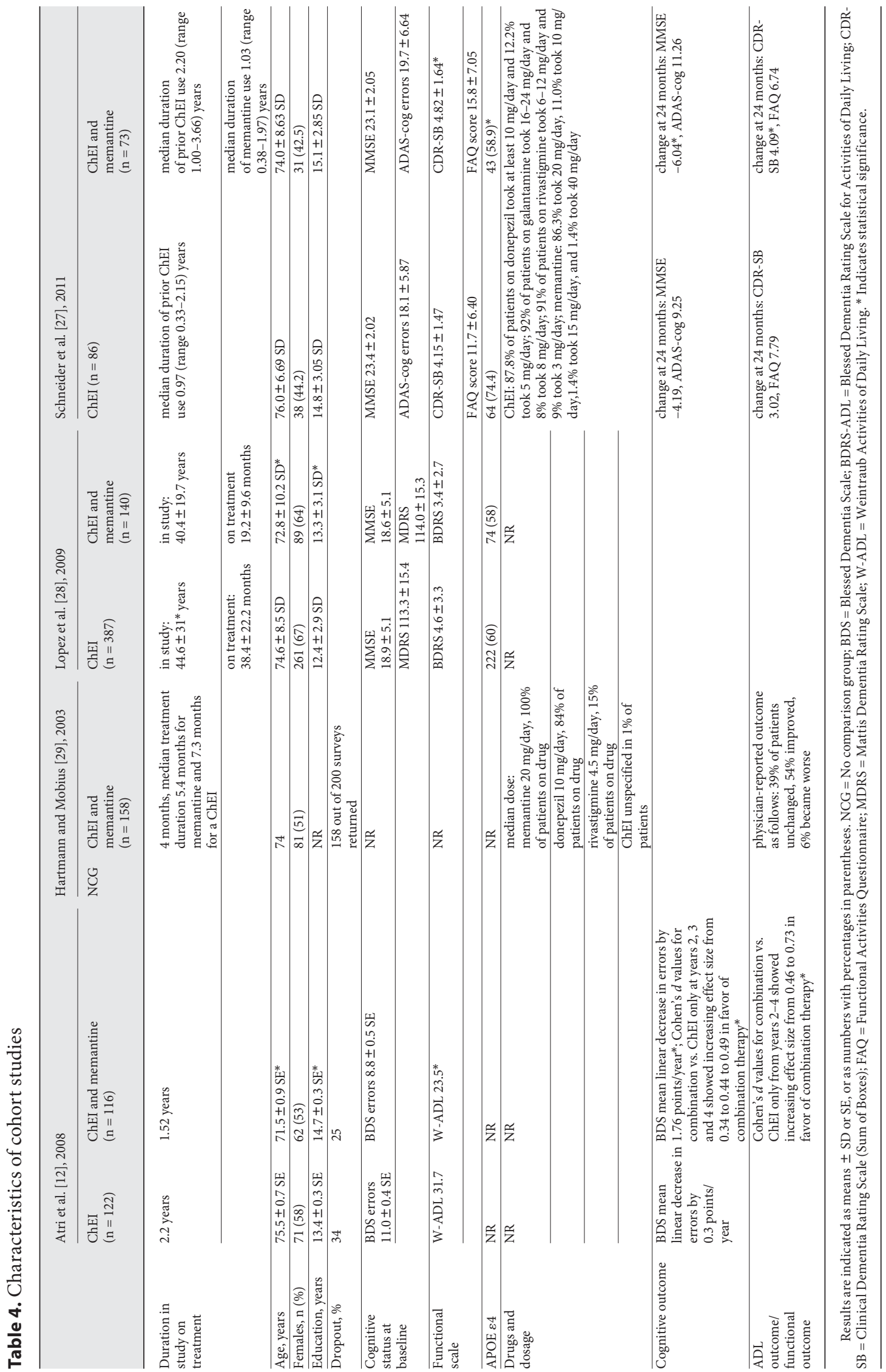


uayqil et al.: Systematic Review and Meta-Analysis of Combination Therapy with

Cholinesterase Inhibitors and Memantine in Alzheimer's Disease and Other Dementias

The study by Howard et al. [21] (DOMINO trial) was a multicenter double-blinded RCT from the UK that enrolled community residents who met the NINCDS-ADRDA criteria for probable or possible AD that was moderate to severe, with an MMSE score between 5 and 13. Patients had been on $10 \mathrm{mg}$ of donepezil for at least 3 months before starting the trial and were eligible for a change in the prescription according to the National Institute for Health and Clinical Excellence guidelines. The study was of a 2 by 2 factorial design and the 295 randomized patients entered 1 of 4 arms: donepezil and placebo, memantine and placebo, donepezil and memantine, or placebo and placebo and were followed for 52 weeks. In general, patients on donepezil or memantine were less likely to withdraw treatment than if not on any of the medications. In an earlier study based on the same cohort [30], the authors defined a minimal clinically important difference (MCID) as a change in the baseline score by 1.4 points on the MMSE, 3.5 points on the Bristol Activities of Daily Living Scale (BADLS), and 8 points on the Neuropsychiatric Inventory (NPI) [21]. This was determined based on the available scores of 127 research patients.

The study by Porsteinsson et al. [20] included 38 centers in the US in a 24-week doubleblinded parallel group RCT that examined patients taking any type of ChEI (donepezil, galantamine, or rivastigmine) with placebo in comparison to taking any of the previously mentioned ChEI with memantine. The patients included in the study were AD patients of mild to moderate severity with an MMSE score ranging from 10 to 22. Patients also had to be on a stable dose of a ChEI for at least 3 months. The NINCDS-ADRDA criteria were also used to determine the presence of probable AD. The total number randomized was 433 (216 on placebo and 217 on memantine), and the ITT population represented 427 patients who had at least one post-baseline assessment.

\section{Cognitive Outcome}

With regard to the outcome of cognitive function, the study by Porsteinsson et al. [20] reported the MMSE and the Alzheimer's Disease Assessment Scale-Cognitive Subscale (ADAS-cog) as outcome measures, both of which did not reach statistical significance. The least squares (LS) mean difference in MMSE between the memantine and placebo groups was reported as 0.5 ( $95 \% \mathrm{CI}-0.1$ to $1.1 ; \mathrm{p}=0.123)$ and with the ADAS-cog reported as -0.7 (95\% CI -1.8 to $0.4 ; \mathrm{p}=0.184)$. The ADAS-cog was one of the primary outcome measures in the study. Another measure was the Severe Impairment Battery (SIB), which was only used in the study by Tariot et al. [13], since it was geared towards patients with severe disease. The LS mean \pm SE estimates of change over time in the placebo and memantine groups, respectively, were $-2.5 \pm 0.69$ and $0.9 \pm 0.67$ (LOCF $\mathrm{p}=0.001$ ). The study by Howard et al. [21] found that the benefit of combination therapy was not superior to continuation with monotherapy. The $\mathrm{p}$ values for the interaction between donepezil and memantine were not significant in any of the outcome measures when looking at the two main comparison groups: continued versus discontinued donepezil and active versus placebo memantine. For patients who continued to take donepezil therapy versus placebo, donepezil patients had a significant change in their MMSE of 2.4 (95\% CI 1.5-3.2) and those who continued on memantine monotherapy had a significant change of 1.7 (95\% CI 0.8-2.5) in the MMSE. These were both compared to the change in patients on combination therapy versus either donepezil monotherapy, which was not significant at 0.8 (95\% CI -0.1 to 1.6), or versus memantine monotherapy 1.5 (95\% CI 0.6-2.3), which was significant.

Pooling of the results of these 3 blinded RCTs, including patients with mild to severe AD, there was no statistically significant change on the continuous outcome measures of cognition when using ChEI in combination with memantine in patients with $\mathrm{AD}$ compared with monotherapy (fig. 2). This was true whether memantine or a ChEI was used in the monotherapy arm from the Howard et al. [21] study or if the MMSE or the ADAS-cog was used in 
uayqil et al.: Systematic Review and Meta-Analysis of Combination Therapy with

Cholinesterase Inhibitors and Memantine in Alzheimer's Disease and Other Dementias

the study by Porsteinsson et al. [20] (fig. 2). In the subgroup analysis that analyzed the two studies that included moderate to severe patients, the effect size was significant in favor of combination therapy $(0.45 ; 95 \%$ CI $0.27-0.63 ; \mathrm{Z}=4.97 ; \mathrm{p}<0.0001)$ versus donepezil monotherapy. It was similarly significant when re-analyzed using memantine as the monotherapy arm from the Howard et al. [21] study (fig. 2). The Tariot et al. [13] study carried 70\% of the weight in the analysis.

\section{Functional Outcome}

ADL were assessed by the AD Cooperative Study-Activities of Daily Living Inventory (ADCS-ADL) in two studies and were a primary outcome measure in the study by Tariot et al. [13], where the LS mean \pm SE change over time between the placebo and memantine groups was $-3.4 \pm 0.51$ and $-2.0 \pm 0.50$, respectively; this was statistically significant (LOCF $\mathrm{p}=0.03$; OC $\mathrm{p}=0.02$ ). As patients were considered to have severe dementia, the 19 -item version of the ADCS-ADL (ADCS- $\mathrm{ADL}_{19}$ ) was used. In the study by Porsteinsson et al. [20], the LS mean difference between the placebo and memantine groups was -0.2 and not statistically significant $(95 \% \mathrm{CI}-1.6$ to 1.3 ; LOCF $\mathrm{p}=0.816$; OC $\mathrm{p}=0.74)$. For this group of patients, considered to have mild to moderate dementia, the 23-item version of the ADCS-ADL $\left(\mathrm{ADCS}-\mathrm{ADL}_{23}\right.$ ) was used. In the Howard et al. [21] study, specifically looking at combination therapy of donepezil and memantine compared to donepezil and placebo (table 2), the BADLS was not significantly different ( -0.5 ; $95 \%$ CI -2.2 to 1.2$)$. On comparison of donepezil and memantine to memantine and placebo, the difference was statistically significant in favor of combination for the BADLS $(-2.0 ; 95 \%$ CI -3.7 to -0.3$)$ but was considered below the MCID.

The meta-analysis using the standardized mean difference did not show a statistically significant effect size when the monotherapy arm from the Howard et al. [21] study was memantine in mild to severe AD. However, it was significant when the agent in the monotherapy arm was donepezil (1.07; 95\% CI 0.26-1.89; $\mathrm{Z}=2.57$; $\mathrm{p}=0.01$; fig. 3 ).

\section{Behavioral Outcome}

In the 3 blinded trials, the behavioral outcome was assessed using the NPI. The LS mean difference was not significantly different between the placebo and memantine groups $(0.3$; $95 \%$ CI -1.7 to 2.4; LOCF $\mathrm{p}=0.743$ ) in the study by Porsteinsson et al. [20], while it was statistically significant in demonstrating a change from baseline in the LS mean \pm SE between the placebo and memantine groups in the study by Tariot et al. [13]: $3.7 \pm 0.99$ and $-0.1 \pm$ 0.98 (LOCF $\mathrm{p}=0.002$ ). When combination therapy of donepezil and memantine was compared to donepezil and placebo in the Howard et al. [21] study, the difference in the NPI was statistically significant in favor of combination $(-5.1 ; 99 \%$ CI -9.8 to -0.3$)$ but did not meet their predetermined MCID. The NPI difference was not significant when the donepezil and memantine group was compared to the memantine and placebo group.

The pooled results did not reach statistical significance when all levels of AD severity were included; however, in moderate to severe disease, an effect size in favor of combination therapy was found to be statistically significant whether memantine or donepezil were in the monotherapy arm (3.7; 95\% CI 11.98-5.43; $\mathrm{Z}=4.21 ; \mathrm{p}<0.0001$ and $4.4 ; 95 \%$ CI 3.01-5.79; $\mathrm{Z}=6.22 ; \mathrm{p}<0.0001$; fig. 4$)$.

The Behavioral Rating Scale for Geriatric Patients care dependency subscale was used only by Tariot et al. [13] as a secondary outcome measure to assess cognitive and functional disability, and the LS mean \pm SE change from baseline was statistically significant for the placebo and memantine groups $(2.3 \pm 0.38$ and $0.8 \pm 0.37$, respectively; LOCF $\mathrm{p}=0.001)$. 
Muayqil et al.: Systematic Review and Meta-Analysis of Combination Therapy with

Cholinesterase Inhibitors and Memantine in Alzheimer's Disease and Other Dementias

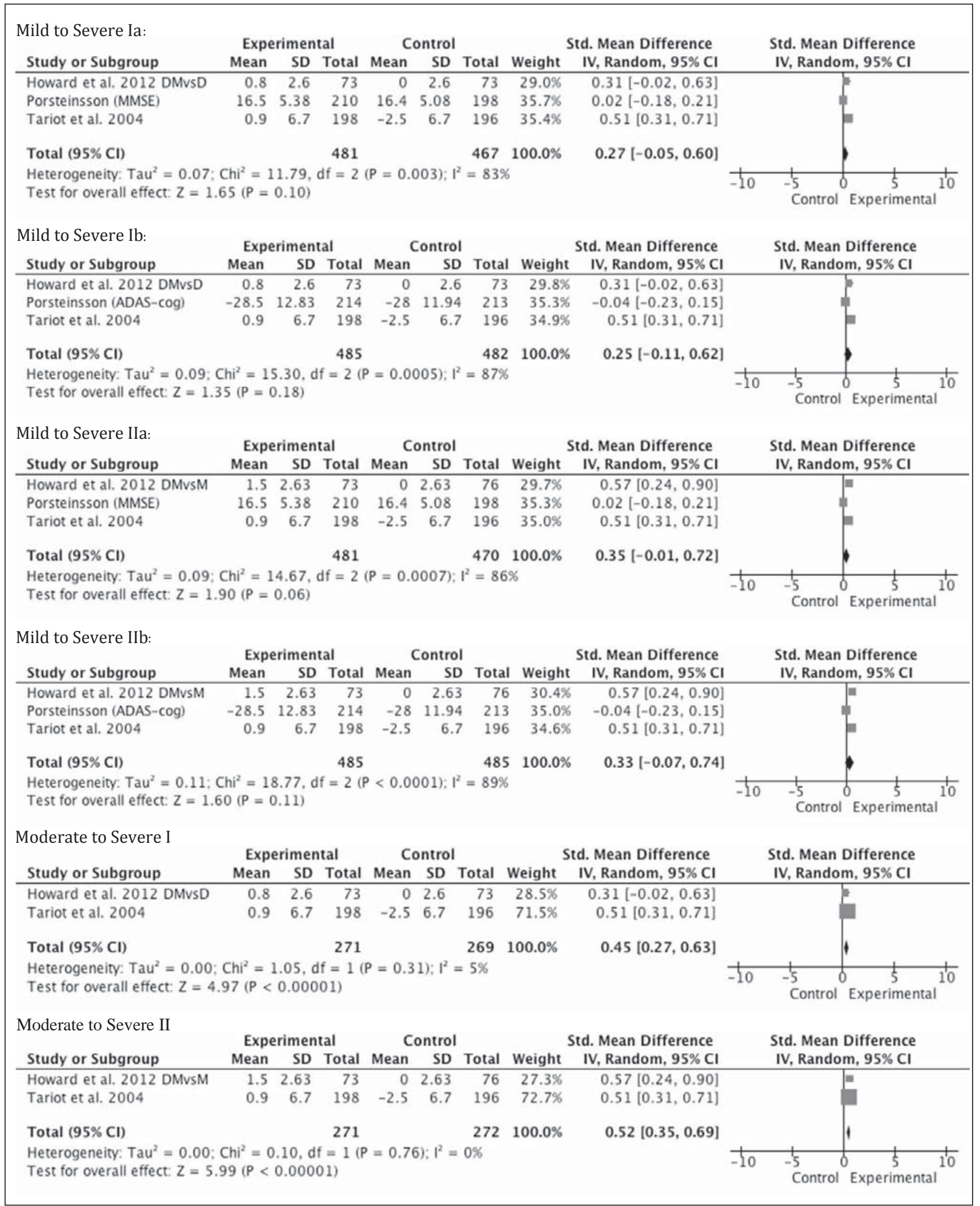

For legend see next page. 


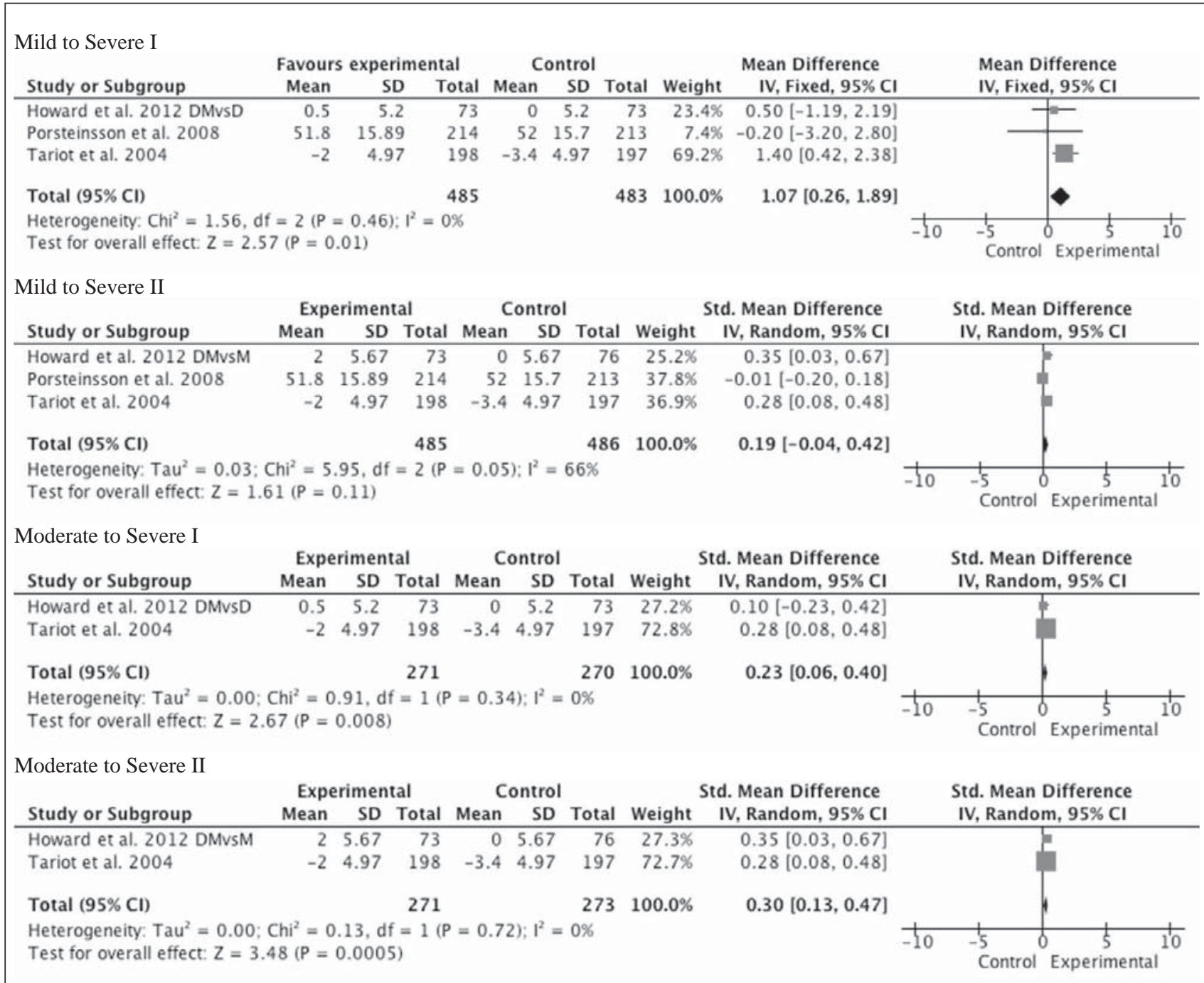

Fig. 3. Metagraphs of functional outcomes of mild to severe (3 studies) and moderate to severe (2 studies) subgroups. DMvsD = Combination therapy with donepezil and memantine versus monotherapy with donepezil, denoted by Roman numeral I; DMvsM = combination therapy with donepezil and memantine versus monotherapy with memantine, denoted by Roman numeral II. Scales used in each study: ADCS$\mathrm{ADL}_{23}$ in Porsteinsson et al. [20], ADCS-ADL 19 in Tariot et al. [13], and BADLS in Howard et al. [21]. Standardized mean differences were used to calculate effect sizes.

Fig. 2. Metagraphs of cognitive outcomes of mild to severe (3 studies) and moderate to severe (2 studies) subgroups. DMvsD = Combination therapy with donepezil and memantine versus monotherapy with donepezil, denoted by Roman numeral I; DMvsM = combination therapy with donepezil and memantine versus monotherapy with memantine, denoted by Roman numeral II. In Porsteinsson et al. [20], MMSE scores were pooled in the results, denoted as 'a'. ADAS-cog scores were pooled in the analysis, denoted as 'b'. Howard et al. [21] used the MMSE, Tariot et al. [13] used the SIB. 
Muayqil et al.: Systematic Review and Meta-Analysis of Combination Therapy with

Cholinesterase Inhibitors and Memantine in Alzheimer's Disease and Other Dementias

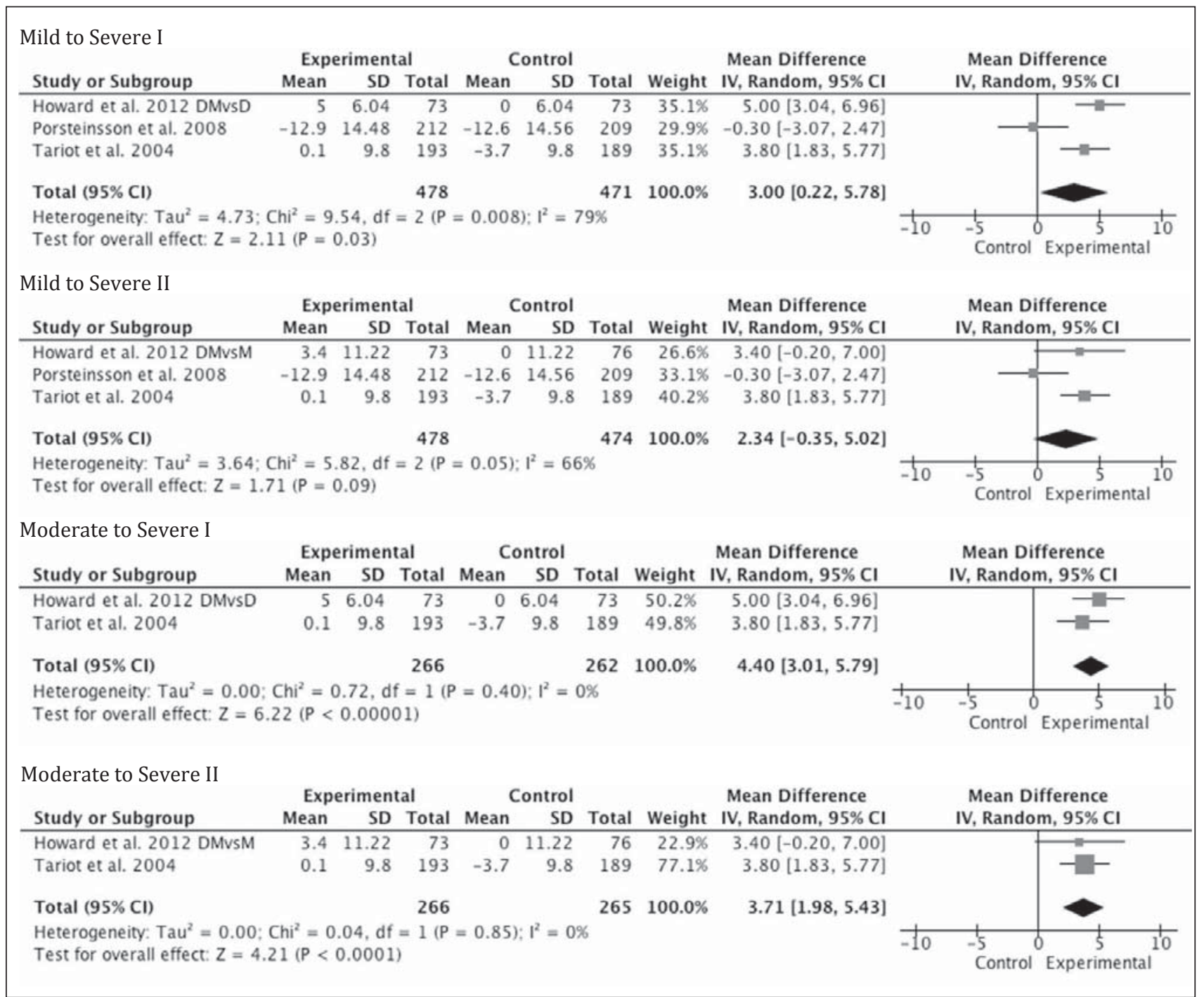

Fig. 4. Metagraphs of behavioral outcomes of mild to severe (3 studies) and moderate to severe (2 studies) subgroups. DMvsD = Combination therapy with donepezil and memantine versus monotherapy with donepezil, denoted by Roman numeral I; DMvsM = combination therapy with donepezil and memantine versus monotherapy with memantine, denoted by Roman numeral II. NPI scale was used in each study and mean differences were used in determining effect sizes.

\begin{tabular}{|c|c|c|c|c|c|c|c|c|c|c|}
\hline \multirow[b]{2}{*}{ Study or Subgroup } & \multicolumn{3}{|c|}{ Experimental } & \multicolumn{3}{|c|}{ Control } & \multirow[b]{2}{*}{ Weight } & \multirow{2}{*}{$\begin{array}{l}\text { Mean Difference } \\
\text { IV, Random, } 95 \% \mathrm{CI}\end{array}$} & \multirow{2}{*}{\multicolumn{2}{|c|}{$\begin{array}{c}\text { Mean Difference } \\
\text { IV, Random, } 95 \% \mathrm{CI}\end{array}$}} \\
\hline & Mean & SD & Total & Mean & SD & Total & & & & \\
\hline Porsteinsson 2008 & 4.38 & 1 & 214 & 4.42 & 0.96 & 213 & $46.0 \%$ & $-0.04[-0.23,0.15]$ & & 1 \\
\hline Tariot 2004 & 4.41 & 0.73 & 198 & 4.66 & 0.74 & 196 & $54.0 \%$ & $-0.25[-0.40,-0.10]$ & & 탄 \\
\hline Total $(95 \% \mathrm{CI})$ & & & 412 & & & 409 & $100.0 \%$ & $-0.15[-0.36,0.05]$ & & 1 \\
\hline \multicolumn{9}{|c|}{$\begin{array}{l}\text { Heterogeneity: } \operatorname{Tau}^{2}=0.01 ; \mathrm{Chi}^{2}=3.04, \mathrm{df}=1(\mathrm{P}=0.08) ; \mathrm{I}^{2}=67 \% \\
\text { Test for overall effect: } \mathrm{Z}=1.47(\mathrm{P}=0.14)\end{array}$} & -10 & $\begin{array}{cccc}-5 & 6 & 5 & 1 \\
\text { Control Experimental } & 10\end{array}$ \\
\hline
\end{tabular}

Fig. 5. Metagraph of performance on CIBIC-Plus, available from 2 studies. 
Balance difficulty, falls or injury I

Control

Odds Ratio

Odds Ratio

Study or Subgroup

Events Total Events Total Weight $\mathrm{M}-\mathrm{H}$, Random, $95 \% \mathrm{Cl}$

$\mathrm{M}-\mathrm{H}$, Random, $95 \% \mathrm{Cl}$

\begin{tabular}{lrrrrrr}
\hline Howard et al. 2012 DMvsD & 3 & 73 & 9 & 73 & $15.1 \%$ & $0.30[0.08,1.18]$ \\
Porsteinsson et al. 2008 & 36 & 217 & 30 & 216 & $45.3 \%$ & $1.23[0.73,2.09]$ \\
Tariot et al. 2004 & 25 & 202 & 20 & 201 & $39.6 \%$ & $1.28[0.69,2.38]$ \\
& & 492 & & 490 & $100.0 \%$ & $1.01[0.56,1.83]$ \\
$\begin{array}{l}\text { Total }(95 \% \mathrm{Cl}) \\
\text { Total events }\end{array}$ & 64 & & 59 & & &
\end{tabular}

Heterogeneity: $\operatorname{Tau}^{2}=0.13 ; \mathrm{Chi}^{2}=3.88, \mathrm{df}=2(\mathrm{P}=0.14) ; \mathrm{I}^{2}=49 \%$

Test for overall effect: $Z=0.04(P=0.97)$

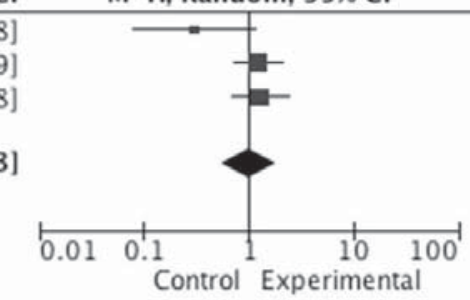

Balance difficulty, falls or injury II

\begin{tabular}{|c|c|c|c|c|c|c|}
\hline \multirow[b]{2}{*}{ Study or Subgroup } & \multicolumn{2}{|c|}{ Experimental } & \multicolumn{2}{|c|}{ Control } & \multirow[b]{2}{*}{ Weight } & \multirow{2}{*}{$\begin{array}{c}\text { Odds Ratio } \\
\text { M- } \mathrm{H} \text {, Random, } 95 \% \mathrm{Cl}\end{array}$} \\
\hline & Events & Total & Events & Total & & \\
\hline Howard et al. 2012 DMvsM & 3 & 73 & 8 & 76 & $11.8 \%$ & $0.36[0.09,1.43]$ \\
\hline Porsteinsson et al. 2008 & 36 & 217 & 30 & 216 & $48.4 \%$ & $1.23[0.73,2.09]$ \\
\hline Tariot et al. 2004 & 25 & 202 & 20 & 201 & $39.8 \%$ & $1.28[0.69,2.38]$ \\
\hline Total $(95 \% \mathrm{Cl})$ & & 492 & & 493 & $100.0 \%$ & $1.08[0.66,1.78]$ \\
\hline Total events & 64 & & 58 & & & \\
\hline
\end{tabular}

Heterogeneity: $\mathrm{Tau}^{2}=0.06 ; \mathrm{Chi}^{2}=2.89, \mathrm{df}=2(\mathrm{P}=0.24) ; \mathrm{I}^{2}=31 \%$

Test for overall effect: $Z=0.31(P=0.75)$

Odds Ratio

M-H, Random, $95 \% \mathrm{Cl}$

Dizziness or nausea I

Study or Subgroup

Experimental Control

Odds Ratio

Events Total Events Total Weight $\mathrm{M}-\mathrm{H}$, Random, $95 \% \mathrm{Cl}$

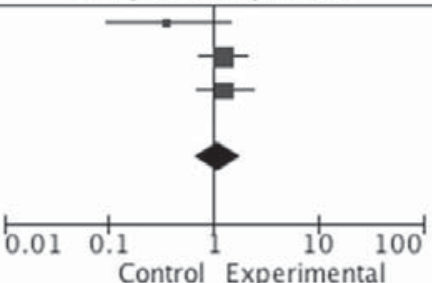

Howard et al. 2012 DMvsD

Porsteinsson et al. 2008

$\begin{array}{rrrrr}0 & 73 & 2 & 73 & 2.8 \% \\ 16 & 217 & 16 & 216 & 50.3 \% \\ 14 & 202 & 16 & 201 & 46.9 \%\end{array}$

$0.19[0.01,4.12]$

$1.00[0.48,2.04]$

Tariot et al. 2004

492

$0.86[0.41,1.81]$

Total $(95 \% \mathrm{Cl})$

30

$490 \quad 100.0 \%$

$0.89[0.53,1.48]$

Heterogeneity: Tau $^{2}=0.00 ; \mathrm{Chi}^{2}=1.06, \mathrm{df}=2(\mathrm{P}=0.59) ; \mathrm{I}^{2}=0 \%$

Test for overall effect: $Z=0.45(P=0.65)$

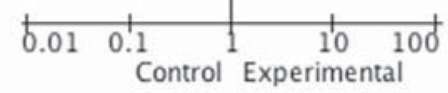

Dizziness or nausea II

Study or Subgroup

Experimental

Control

Odds Ratio

Odds Ratio

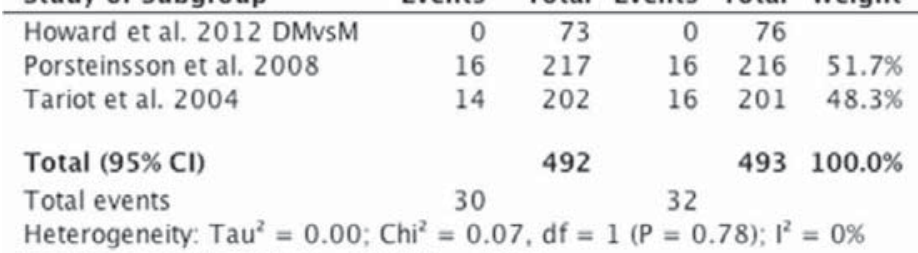

$1(P=0.78): I^{2}=0 \%$

Test for overall effect: $Z=0.28(P=0.78)$

Random, 95\% Cl

M-H, Random, 95\% Cl $1.00[0.48,2.04]$

$0.86[0.41,1.81]$

$0.93[0.55,1.56]$

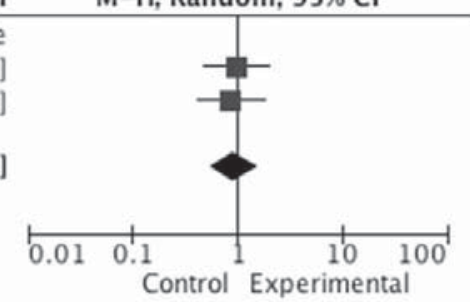

Gastrointestinal I

Study or Subgroup

Experimental Control

Odds Ratio

Howard et al. 2012 DMvsD

Events

Total Events

Weight M-H, Random, $95 \% \mathrm{Cl}$

Odds Ratio

Porsteinsson et al. 2008

$\begin{array}{lllll}7 & 73 & 5 & 73 & 21.2 \%\end{array}$

$\begin{array}{lllll}12 & 217 & 14 & 216 & 36.5 \%\end{array}$

$\begin{array}{lllll}13 & 202 & 27 & 201 & 42.3 \%\end{array}$

$1.44[0.44,4.77]$

$0.84[0.38,1.87]$

Tariot et al. 2004

492

$490 \quad 100.0 \%$

$0.44[0.22,0.89]$

Total $(95 \% \mathrm{Cl})$

32 46

Heterogeneity: Tau $^{2}=0.12 ; \mathrm{Chi}^{2}=3.27, \mathrm{df}=2(\mathrm{P}=0.20) ; \mathrm{I}^{2}=39 \%$

Test for overall effect: $Z=1.01(P=0.31)$

$0.72[0.38,1.36]$

Figure continued on next page.

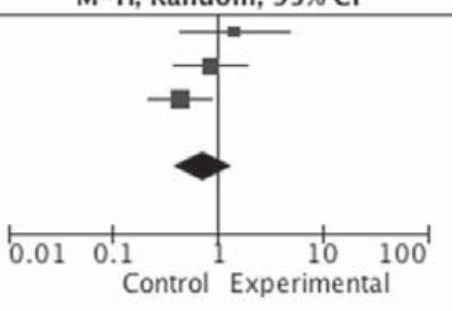




\begin{tabular}{|c|c|c|c|c|c|c|c|}
\hline \multicolumn{8}{|l|}{ Gastrointestinal II } \\
\hline \multirow[b]{2}{*}{ Study or Subgroup } & \multicolumn{2}{|c|}{ Experimental } & \multicolumn{2}{|c|}{ Control } & \multirow[b]{2}{*}{ Weight } & \multirow{2}{*}{$\begin{array}{c}\text { Odds Ratio } \\
\mathrm{M}-\mathrm{H} \text {, Random, } 95 \% \mathrm{Cl}\end{array}$} & \multirow{2}{*}{$\begin{array}{c}\text { Odds Ratio } \\
\mathrm{M}-\mathrm{H}, \text { Random, } 95 \% \mathrm{Cl}\end{array}$} \\
\hline & Events & Total & Events & Total & & & \\
\hline Howard et al. 2012 DMvsM & 7 & 73 & 3 & 76 & $22.3 \%$ & $2.58[0.64,10.39]$ & \begin{tabular}{c|c} 
& $\square-$
\end{tabular} \\
\hline Porsteinsson et al. 2008 & 12 & 217 & 14 & 216 & $37.3 \%$ & $0.84[0.38,1.87]$ & \\
\hline Tariot et al. 2004 & 13 & 202 & 27 & 201 & $40.4 \%$ & $0.44[0.22,0.89]$ & \\
\hline Total $(95 \% \mathrm{CI})$ & & 492 & & 493 & $100.0 \%$ & $0.83[0.36,1.96]$ & \\
\hline Total events & 32 & & 44 & & & & \\
\hline $\begin{array}{l}\text { Heterogeneity: } \mathrm{Tau}^{2}=0.34 ; \\
\text { Test for overall effect: } \mathrm{Z}=0\end{array}$ & $\begin{array}{l}\mathrm{Chi}^{2}=5.2 \\
42(\mathrm{P}=0\end{array}$ & $\begin{array}{l}6, \mathrm{df}= \\
68)\end{array}$ & $2(P=0$ & $.07) ; 1^{2}$ & $=62 \%$ & & 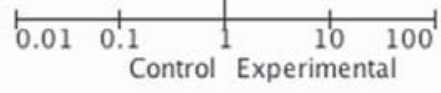 \\
\hline \multicolumn{8}{|l|}{ Neurobehavioral I } \\
\hline & \multicolumn{2}{|c|}{ Experimental } & \multicolumn{2}{|c|}{ Control } & \multirow[b]{2}{*}{ Weight } & \multirow{2}{*}{$\begin{array}{c}\text { Odds Ratio } \\
\mathrm{M}-\mathrm{H} \text {, Random, } 95 \% \mathrm{Cl}\end{array}$} & \multirow{2}{*}{$\begin{array}{c}\text { Odds Ratio } \\
\mathrm{M}-\mathrm{H}, \text { Random, } 95 \% \mathrm{Cl}\end{array}$} \\
\hline Study or Subgroup & Events & Total & Events & Total & & & \\
\hline Howard et al. 2012 DMvsD & 8 & 73 & 7 & 73 & $10.0 \%$ & $1.16[0.40,3.39]$ & \\
\hline Porsteinsson et al. 2008 & 43 & 217 & 41 & 216 & $50.6 \%$ & $1.05[0.65,1.70]$ & \\
\hline Tariot et al. 2004 & 35 & 202 & 28 & 201 & $39.3 \%$ & $1.29[0.75,2.22]$ & \\
\hline Total $(95 \% \mathrm{CI})$ & & 492 & & 490 & $100.0 \%$ & $1.15[0.82,1.62]$ & \\
\hline Total events & 86 & & 76 & & & & \\
\hline $\begin{array}{l}\text { Heterogeneity: } \operatorname{Tau}^{2}=0.00 \\
\text { Test for overall effect: } Z=0\end{array}$ & $\begin{array}{l}\mathrm{Chi}^{2}=0 . \\
83(P=0\end{array}$ & $\begin{array}{l}31, \mathrm{df}= \\
41)\end{array}$ & $2(P=0$ & $0.86) ; 1^{2}$ & $=0 \%$ & & \begin{tabular}{|lc|c|}
0.01 & 0.1 & 1 \\
& \multicolumn{1}{c|}{ Control Experimental } & 100
\end{tabular} \\
\hline \multicolumn{8}{|l|}{ Neurobehavioral II } \\
\hline & \multicolumn{2}{|c|}{ Experimental } & \multicolumn{2}{|c|}{ Control } & \multirow[b]{2}{*}{ Weight } & \multirow{2}{*}{$\begin{array}{c}\text { Odds Ratio } \\
\mathrm{M}-\mathrm{H} \text {, Random, } 95 \% \mathrm{Cl}\end{array}$} & \multirow{2}{*}{$\begin{array}{l}\text { Odds Ratio } \\
\mathrm{M}-\mathrm{H}, \text { Random, } 95 \% \mathrm{Cl}\end{array}$} \\
\hline Study or Subgroup & Events & Total & Events & Total & & & \\
\hline Howard et al. 2012 DMvsM & 8 & 73 & 7 & 76 & $10.0 \%$ & $1.21[0.42,3.53]$ & \\
\hline Porsteinsson et al. 2008 & 43 & 217 & 41 & 216 & $50.6 \%$ & $1.05[0.65,1.70]$ & \\
\hline Tariot et al. 2004 & 35 & 202 & 28 & 201 & $39.3 \%$ & $1.29[0.75,2.22]$ & \\
\hline Total $(95 \% \mathrm{Cl})$ & & 492 & & 493 & $100.0 \%$ & $1.16[0.83,1.63]$ & \\
\hline Total events & 86 & & 76 & & & & \\
\hline $\begin{array}{l}\text { Heterogeneity: } \operatorname{Tau}^{2}=0.00 \\
\text { Test for overall effect: } Z=0\end{array}$ & $\begin{array}{l}\mathrm{Chi}^{2}=0 . \\
86(P=0\end{array}$ & $\begin{array}{l}32, \mathrm{df}= \\
.39)\end{array}$ & $2(P=0$ & $0.85) ; 1^{2}$ & $=0 \%$ & & \begin{tabular}{|lc|cc|}
0.01 & 0.1 & 10 & 100 \\
& \multicolumn{1}{c|}{ Control } & 10 \\
& & Experimental
\end{tabular} \\
\hline \multicolumn{8}{|l|}{ Flu-Like symptoms I } \\
\hline & \multicolumn{2}{|c|}{ Experimental } & \multicolumn{2}{|c|}{ Control } & \multirow[b]{2}{*}{ Weight } & Odds Ratio & Odds Ratio \\
\hline Study or Subgroup & Events & Total & Events & Total & & M-H, Random, 95\% Cl & M-H, Random, 95\% Cl \\
\hline Howard et al. 2012 DMvsD & 5 & 73 & 6 & 73 & $15.0 \%$ & $0.82[0.24,2.82]$ & \begin{tabular}{l|l}
$\longrightarrow$ & \\
$\longrightarrow$
\end{tabular} \\
\hline Porsteinsson et al. 2008 & 38 & 217 & 22 & 216 & $43.4 \%$ & $1.87[1.07,3.29]$ & \\
\hline Tariot et al. 2004 & 25 & 202 & 26 & 201 & $41.6 \%$ & $0.95[0.53,1.71]$ & \\
\hline Total $(95 \% \mathrm{CI})$ & & 492 & & 490 & $100.0 \%$ & $1.25[0.74,2.11]$ & \\
\hline Total events & 68 & & 54 & & & & \\
\hline $\begin{array}{l}\text { Heterogeneity: } \mathrm{Tau}^{2}=0.08 \\
\text { Test for overall effect: } Z=0\end{array}$ & $\begin{array}{l}\mathrm{Chi}^{2}=3 . \\
83(\mathrm{P}=0\end{array}$ & $\begin{array}{l}23, \mathrm{df}= \\
41)\end{array}$ & $2(P=0$ & $.20) ; 1^{2}$ & $=38 \%$ & & 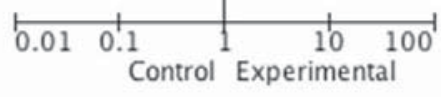 \\
\hline Flu-Like symptoms II & & & & & & & \\
\hline & Experim & lental & Contr & rol & & Odds Ratio & Odds Ratio \\
\hline Study or Subgroup & Events & Total & Events & Total & Weight & M-H, Random, 95\% Cl & M-H, Random, 95\% Cl \\
\hline Howard et al. 2012 DMvsD & 5 & 73 & 6 & 73 & $15.0 \%$ & $0.82[0.24,2.82]$ & \begin{tabular}{l|l}
$\rightarrow$ \\
\end{tabular} \\
\hline Porsteinsson et al. 2008 & 38 & 217 & 22 & 216 & $43.4 \%$ & $1.87[1.07,3.29]$ & \\
\hline Tariot et al. 2004 & 25 & 202 & 26 & 201 & $41.6 \%$ & $0.95[0.53,1.71]$ & \\
\hline Total $(95 \% \mathrm{Cl})$ & & 492 & & 490 & $100.0 \%$ & $1.25[0.74,2.11]$ & \\
\hline Total events & 68 & & 54 & & & & \\
\hline $\begin{array}{l}\text { Heterogeneity: } \operatorname{Tau}^{2}=0.08 \text {; } \\
\text { Test for overall effect: } Z=0\end{array}$ & $\begin{array}{l}\mathrm{Chi}^{2}=3 . \\
83(\mathrm{P}=0\end{array}$ & $\begin{array}{l}23, \mathrm{df}= \\
41)\end{array}$ & $2(P=0$ & $.20) ; 1^{2}$ & $=38 \%$ & & \begin{tabular}{|ll|c|}
0.01 & 0.1 & 1 \\
& Control Experimental & 100 \\
\end{tabular} \\
\hline
\end{tabular}

Figure continued on next page. 


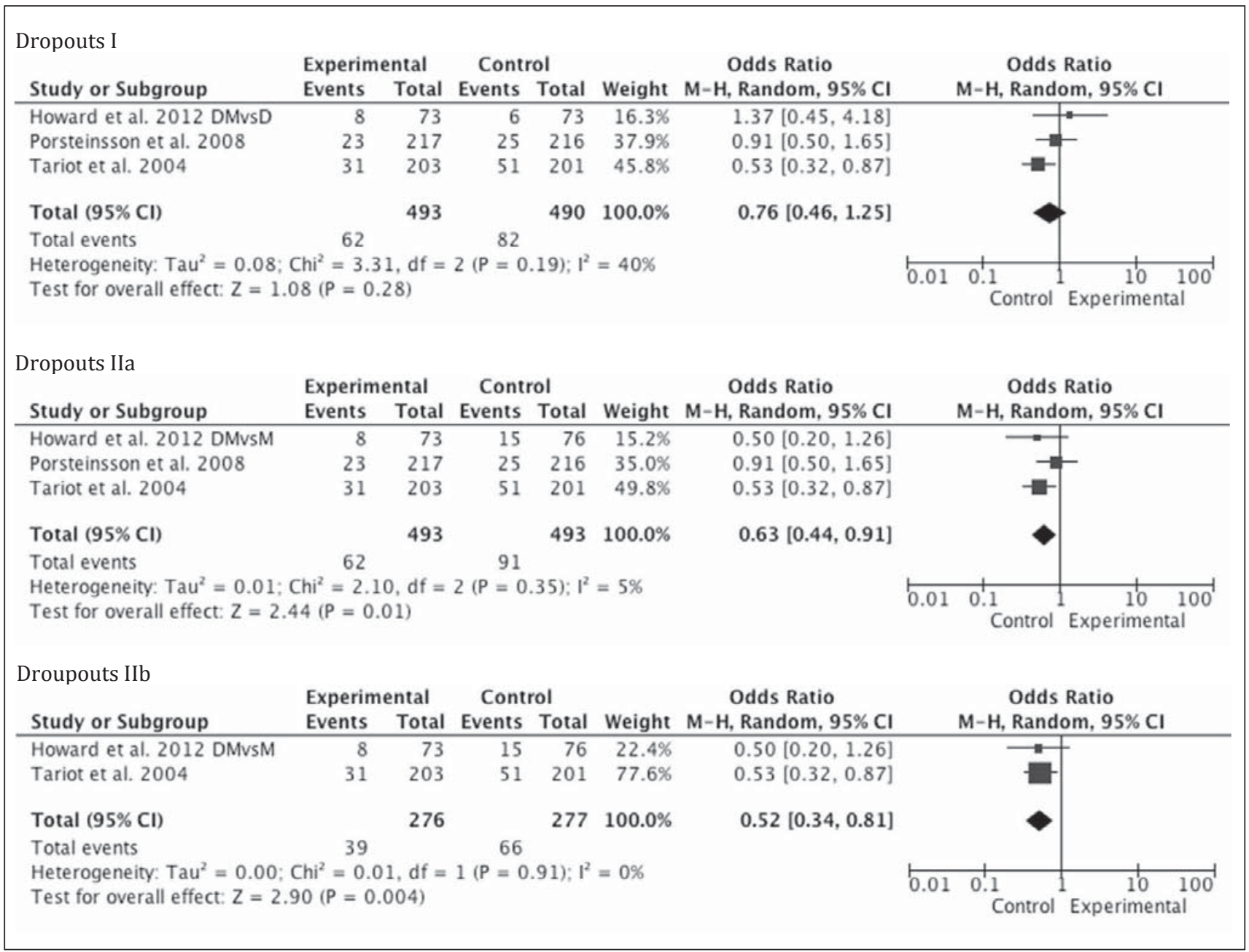

Fig. 6. Metagraphs of adverse outcomes of mild to severe AD (3 studies). DMvsD = Combination therapy with donepezil and memantine versus monotherapy with donepezil, denoted by Roman numeral I; DMvsM = combination therapy with donepezil and memantine versus monotherapy with memantine, denoted by Roman numeral II. The only significant results were from the analysis shown in 'Dropouts II', IIa denoting mild to severe and IIb denoting moderate to severe subgroups.

\section{Global Outcome}

The Clinician's Interview-Based Impression of Change Plus Caregiver Input (CIBICPlus), which tends to assess multiple aspects of patients' performance in cognitive, behavioral, and functional domains, was a primary outcome measure in the trial by Porsteinsson et al. [20] and a secondary outcome measure in the trial by Tariot et al. [13]. Because it is a measure of change from baseline, there is no rating of performance during enrollment into the study. In the study by Porsteinsson et al. [20], the LS mean difference between the memantine and placebo groups was $0.0(95 \% \mathrm{CI}-0.2$ to 0.2 ; LOCF p $=0.843)$ and in Tariot et al. [13], the LS mean \pm SE change from baseline in the placebo and memantine group was $4.66 \pm 0.075$ and $4.41 \pm 0.074$, respectively (LOCF $\mathrm{p}=0.03$ ). The OC analysis had $\mathrm{p}$ values of similar significance, 0.65 in Porsteinsson et al. [20] and 0.03 in Tariot et al. [13]; however, the effect size in the meta-analysis was not statistically significant $(\mathrm{p}=0.14$; fig. 5). 
Muayqil et al.: Systematic Review and Meta-Analysis of Combination Therapy with

Cholinesterase Inhibitors and Memantine in Alzheimer's Disease and Other Dementias

Quality of Life

The study by Howard et al. [21] was the only one to use a quality of life measure. The change in the DEMQOL-proxy was not found to be significant in any of the treatment groups.

Adverse Effects and Dropouts

Adverse effects in general were infrequent and occurred in about 3-5\% patients of the 3 studies (table 5), none of which were statistically significant, even after excluding the mild to moderate AD patients of Porsteinsson et al. [20]. There were more dropouts in the control groups. This was not significant when the monotherapy arm of the Howard et al. [21] study was donepezil and after removal of the study by Porsteinsson et al. [20] from the analysis. However, more dropouts occurred when the monotherapy arm of the Howard et al. [21] study was memantine in the control groups. This was true even after controlling for the mild to moderate group (fig. 6).

\section{Discussion}

Studies in dementia treatment thus far have yielded findings that suggest modest benefits using ChEI in combination with memantine in patients with $\mathrm{AD}$ based on the effect sizes. The pooled results in this review showed that there was no statistically significant change on the continuous outcome measures of cognition in patients with mild to severe dementia. Study patients had MMSE ranges of 5-14 in Tariot et al. [13], 5-13 in Howard et al. [21], and 10-22 in Porsteinsson et al. [20]; thus, all groups had some overlap in severity of dementia. The 3 trials lacked clear definitions of how mild to moderate disease is discriminated from moderate to severe disease, apart from the MMSE scores. Because of these issues, analyzing all levels of severity was warranted prior to the subgroup analysis. A statistically significant effect size in favor of combination therapy was appreciated in the subgroup analysis when patients with mild to moderate disease were excluded. The study by Tariot et al. [13], which found statistically significant improvement, measured cognition using the SIB, which is geared towards patients with advanced dementia, avoiding the floor effect [31] that can occur with the MMSE in similar patients. The floor effect may have attenuated the results of the DOMINO trial, which used the MMSE in its cohort of moderate to severe AD patients. In the DOMINO trial, combination therapy was not significantly better than donepezil alone, and it did not result in an MMSE change as large as when continuing monotherapy with either donepezil or memantine. This latter finding highlights what is already current practice, namely the positive effect of memantine in moderate to severe disease [32], and also suggests a potential role for the continuation of donepezil monotherapy rather than its discontinuation.

Although the cohort studies in general did not provide detailed information on the severity of $A D$ in their patients, the article by Schneider et al. [27], which included patients with mild AD, did not show benefit with combination therapy. A similar pattern was appreciated among the open-label trials as well; the study by Riepe et al. [24] included mild to moderate disease, and although there was an observed benefit, it was most evident at the more severe end of the cognitive spectrum. In the study by Atri et al. [12], patients on therapy were assessed between 1997 and 2005; this suggests heterogeneity between patients enrolled in the study, as both pharmacological and non-pharmacological conservative interventions for relevant risk factors may have changed over the years.

Meta-analysis of the functional outcome scales from the 3 blinded-RCTs using the standardized mean difference showed a significant effect size in favor of combination therapy when the monotherapy arm of the DOMINO trial was memantine, but not when it was done- 
Dementia

Cognitive Disorders
Dement Geriatr Cogn Disord Extra 2012;2:546-572

\begin{tabular}{l|l}
\hline DOI: $10.1159 / 000343479$ & (c) 2012 S. Karger AG, Base
\end{tabular}

Published online: November 23, 2012

www.karger.com/dee

(1)

Cholinesterase Inhibitors and Memantine in Alzheimer's Disease and Other Dementias

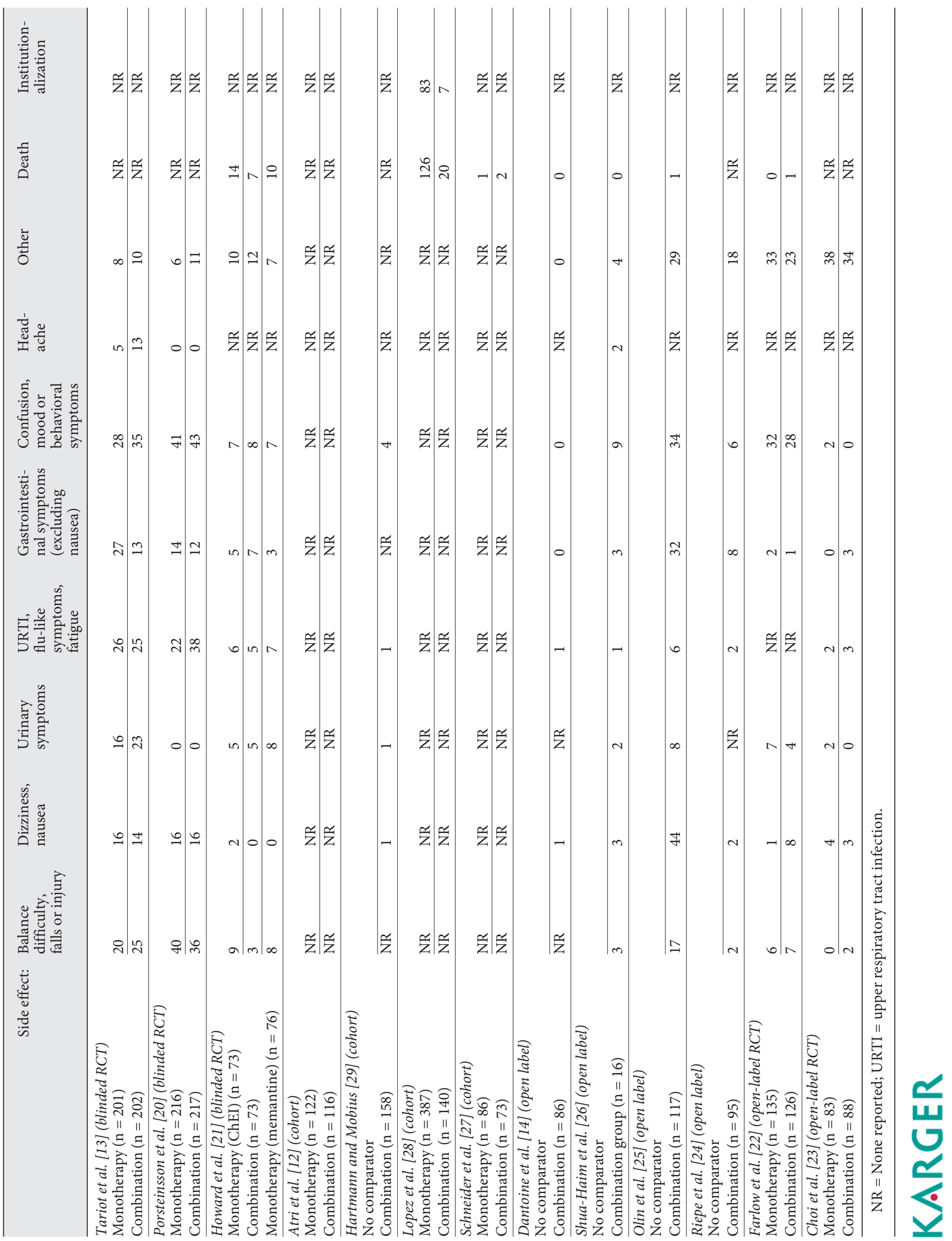


pezil. This is probably explained by the large weight Tariot et al. [13] carried in the analysis $(\sim 70 \%)$ in this comparison, thus requiring a conservative interpretation of the result, whereas the weight was more evenly distributed when the monotherapy arm was donepezil and the result was not significant (fig. 3). Tariot et al. [13] also carried significant weight in the moderate to severe subgroup analyses. The study showed improvement in their patients with moderate to severe dementia as measured with the ADSC-ADL $\mathrm{A}_{19}$, while no improvement was seen in the Porsteinsson et al. [20] study with patients in the mild to moderate range and measured by the ADCS-ADL 23 . Each of these studies used a version of the ADCS-ADL that is the most suited to detect change in their population [33], as did the DOMINO trial which used the BADL. Additionally, the study by Porsteinsson et al. [20] used the ADCS-ADL 23 as a secondary outcome measure. In the few cohort and open-label studies that found improvement in functional outcomes, patients' condition varied in severity, but they were mainly in the moderate to severe range; however, no improvement was observed on caregiver assessment of ADL. The CIBIC-Plus results revealed statistically significant improvements in the moderate to severe AD patients from the Tariot et al. [13] study, where it was a primary outcome measure, and no improvement in the mild to moderate AD patients from the Porsteinsson et al. [20] study, where it was a secondary outcome measure. In addition to these measurement discrepancies, there has been concern about the reliability of the CIBIC-Plus and its relative insensitivity to detect change [34-36].

Three out of the 4 subgroup analyses assessing the neurobehavioral outcomes with the NPI showed that it was statistically significant in favor of combination therapy (fig. 4). Interestingly, the NPI was significant in the more advanced dementia groups from Tariot et al. [13], and when combination was compared with memantine monotherapy, in Howard et al. [21]. There is some concern about variability in administration and scoring of the NPI [37]. The NPI was also a secondary outcome measure in all 3 trials, and the studies were not primarily powered to detect changes in the NPI. This significant finding deserves further investigation as a primary outcome measure.

Memantine was not examined as monotherapy in any of the studies except for the DOMINO trial [21]. Thus, certainty cannot be obtained from any of the other trials that show benefit of combination therapy, as none controlled for potential benefit from memantine alone.

In the blinded RCTs, there were significantly more dropouts from the control groups in the pooled analysis of all 3 trials and in the subgroup analysis of moderate to severe dementia, when the monotherapy arm from the DOMINO trial was memantine. Tariot et al. [13] suggest that with more dropouts in the control group (OR 1.89; 95\% CI 1.15-3.1), there is a possibility of underestimating the effect of memantine. Alternatively, a general argument can be made that better patient adherence is associated with better patient outcome [38]. The 3 trials use LOCF in their ITT population, which is commonly used in dementia studies. This method has been challenged [39] because it can lead to measurement bias, as the patients who drop out will have their last observation reported as their final outcome, leading the investigator to act on the assumption that the disease has stopped progressing, thus falsely overestimating the effect of a treatment arm or underestimating the effect of treatment if dropouts were more in the placebo arm. However, the results were not very different the OC analysis. The dropout rates were overall low in the remaining studies that reported it, and the medications appear to be well tolerated.

Limitations of this review include the need to convert SEs to SDs and the use of standard mean differences in calculating the effect size of cognitive and functional outcomes as each of the studies used separate or different versions of scales. There are few studies included in this review, and the paucity of literature in this area makes it difficult to come to a definite conclusion. Publication bias is possible, and we were not able to perform a funnel plot because of the low number of studies analyzed. The varying severity of AD in the patients in- 
cluded in the different studies and the different ChEIs used in one of the blinded RCTs also are limitations. Fortunately, analyzing moderate to severe cases only helped limit the ChEI analyzed to donepezil. Conversely, including all ChEI in the analysis has the benefit of identifying a drug class effect [18].

Estimations provided by effect sizes are not optimal for describing MCID [40], particularly with the pooling of performance from different scales. Therefore, prior to concluding, the issue of how meaningful these changes are must be examined. In other words, are these changes significant on a clinical level or do they merely represent changes in scores without really impacting the patient or family? Jaeschke et al. [41] provided a definition for what is known as the MCID: 'The smallest difference in score in the domain of interest which patients perceive as beneficial and which would mandate, in the absence of troublesome side effects and excessive cost, a change in the patient's management.' Looking at each of the blinded RCTs, we find that Howard et al. [21] is the only study that derived an MCID from their own population, while the other two used the CIBIC-Plus as an indicator of clinical impact, and only Tariot et al. [13] showed a significant change in the CIBIC-Plus in favor of combination. The probability of the MCID also being different with differing AD severity levels has previously been raised [42]. Burback et al. [42] suggest that larger sample sizes and observing patients in trials for at least 1 year is required before being able to detect an MCID. In this review, only the DOMINO trial observed patients for 1 year.

A systematic review of ChEIs in comparison to placebo in AD patients found a mean change that was beneath the US Food and Drug Administration's consensus proposed MCID of 4 , as measured by the ADAS-cog, ranging from 1.5 to 3.9 points $[43,44]$. Despite this interesting finding, ChEIs are routinely used and appreciated; so, determining what exactly is an appropriate MCID remains elusive. It is likely to vary at a population level, if not at an individual level.

In summary, an effect was seen in moderate to severe $\mathrm{AD}$ patients; however, we believe that this finding should be interpreted cautiously, due to concerns about the weight of one of the studies and the fact that the MCID was not reached despite statistical significant improvement on a scale in another study. A recommendation to use combination therapy in the form of memantine in conjunction with a ChEI to reduce deterioration in cognition or function in patients with any type of dementia, including $\mathrm{AD}$, cannot be made at this time. The significant effect sizes observed in this analysis suggest that further trials exploring combination therapy, particularly in moderate to severe $\mathrm{AD}$, are warranted. Attributing the improvement seen in some studies of $\mathrm{AD}$ patients to combination therapy will require further blinded RCTs that replicate these results and have separate monotherapy arms of memantine and a ChEI. The definition of dementia type, as well as dementia severity, should also be clearly formulated. Trials should also consider using mixed models in their analysis that may yield less biased results than the OC or LOCF approaches [45]. Combination therapy appears to be safe and well tolerated when compared to monotherapy. No conclusions can be made on the use of combination therapy in other forms of dementia at this time given the absence of adequate studies.

Other recommendations for future research would be assessing the response to combination therapy with a behavioral measure as the primary outcome. Investigating the response in patients with various comorbidities that are encountered commonly in the geriatric population such as diabetes, hypertension and hyperlipidemia, and exploring the influence of biomarkers, such APOE $\varepsilon 4$ status, cerebrospinal fluid tau and amyloid protein, and emerging neuroimaging techniques would also be rewarding. More trials researching response in other dementia types are also recommended. 


\section{Appendix 1}

\section{Search Strategy and Terms}

(1) exp memantine/or (memantin* or ebixa or akatinol or namenda or axura).mp. [mp = protocol supplementary concept, rare disease supplementary concept, title, original title, abstract, name of substance word, subject heading word, unique identifier]

(2) exp donepezil/or (donepezil or aricept or eranz).mp. [ $\mathrm{mp}=$ protocol supplementary concept, rare disease supplementary concept, title, original title, abstract, name of substance word, subject heading word, unique identifier]

(3) exp galantamine/or (galantamine or nivalin or reminyl).mp. [mp = protocol supplementary concept, rare disease supplementary concept, title, original title, abstract, name of substance word, subject heading word, unique identifier]

(4) exp rivastigmine/or (rivastigmine or prometax or exelon). $\mathrm{mp}$. [ $\mathrm{mp}=$ protocol supplementary concept, rare disease supplementary concept, title, original title, abstract, name of substance word, subject heading word, unique identifier]

(5) exp tacrine/or (tacrine or cognex).mp. [mp = protocol supplementary concept, rare disease supplementary concept, title, original title, abstract, name of substance word, subject heading word, unique identifier]

(6) dementia.mp. or exp Delirium, Dementia, Amnestic, Cognitive Disorders/or exp Dementia, Vascular/or exp Dementia, Multi-Infarct/or exp Dementia/or exp Frontotemporal Dementia/

(7) lewy body dementia.mp. or exp Lewy Body Disease/

(8) exp Cholinesterase Inhibitors/or cholinesterase inhibitor*.mp.

(9) exp Parkinson Disease/or parkinson* disease dementia.mp.

(10) exp Alzheimer Disease/or exp Cognition/or exp Dementia/or exp Aged/or exp Cognition Disorders/or cognitive decline.mp. or exp Aging/

(11) exp Memory Disorders/or exp Cognition Disorders/or exp Cognition/or mild cognitive impairment.mp.

(12) exp Parkinson Disease/or parkinson* disease dementia.mp.

(13) 2 or 3 or 4 or 5 or 8

(14) 6 or 7 or 9 or 10 or 11 or 12

(15) 1 and 13 and 14

\section{Appendix 2}

\section{Non-RCTs}

Cohort Studies

In a prospective cohort study by Atri et al. [12], 382 patients with a diagnosis of probable AD by NINCDS-ADRDA criteria were recruited at the Massachusetts General Hospital. The study included 3 arms, 1 without any pharmacological therapy $(\mathrm{n}=144), 1$ with ChEI $(n=122)$ alone, and 1 with the combination of a ChEI and memantine $(n=116)$. The patients who were not on any therapy were enrolled before 1995 when use of such drugs was not routine and the remaining patients were assessed between 1997 and 2005. The total time on medication was calculated with the consideration that there were gaps in the treatment period that were not incorporated into the total time on medication; the exact duration and frequency of these gaps are not reported. Significant differences were found at baseline (table 4) and adjusted for during the statistical analysis. With regard to their performance on the Blessed Dementia Scale, patients in the combination therapy group had a statistically significant slower rate of increase in errors across the years of the study when compared to 
uayqil et al.: Systematic Review and Meta-Analysis of Combination Therapy with

Cholinesterase Inhibitors and Memantine in Alzheimer's Disease and Other Dementias

the other two groups $(p<0.001)$. In the assessment of the ADL, a ceiling effect was noted with the Weintraub Activities of Daily Living scale, where those with higher baseline dependency scores progressed at a slower rate than those with a lower baseline dependency score $(\mathrm{p}=0.01)$. Additionally, the combination therapy group showed a slower increase in dependency that was statistically significant $(\mathrm{p}=0.001)$. The paper did not address adverse effects.

The study by Hartmann and Mobius [29] was a post-marketing surveillance study in Germany, where a few years after the release of memantine into the market, 200 questionnaires were mailed out to physicians who were asked to look for particular changes in their patients over the ensuing 4 months regardless of the type of dementia. It was up to the physician to choose which of his patients on combination therapy were to be followed and reported in the study. Scales to determine tolerability and impression of treatment success appear subjective and are not referenced as validated measures. Only exploratory statistics were used in the study analysis. Reports from 158 surveyed patients were returned: 121 patients (77\%) had $\mathrm{AD}, 14$ (9\%) had vascular dementia, and a specific diagnosis was not provided for the rest. Physicians documented that the condition remained unchanged in $39 \%$ of patients following the combination therapy, improved in 54\%, and worsened in $6 \%$.

Lopez et al. [28] examined a cohort of patients retrospectively who had at least a 1-year follow-up evaluation at the University of Pittsburgh spanning a period from 1983 to 2004. Out of 1,539 patients who met the NINCDS-ADRDA criteria for probable AD, they examined 943 patients. The 596 patients who were not followed up were more likely to be older, African-American, less educated, and had a longer duration of symptoms. Among the 943 patients, 140 (14.9\%) used combination treatment, 387 (45.0\%) used only a ChEI, and 416 (40.1\%) were not on therapy. Nursing home admission was the primary outcome of interest in the article, and there were fewer admissions in the combination group at 1-year follow-up ( $\mathrm{p}<0.001)$. The hazard ratio for nursing home admission was 0.29 (95\% CI 0.11-0.72) for patients on combination therapy compared to those on ChEI alone. The combination group was followed for 4 months less than the ChEI group and 22 months less than the no-medication group.

Lastly, among the cohort studies, a study by Schneider et al. [27] assessed patients from 59 US and Canadian sites out of the Alzheimer's Disease Neuroimaging Initiative. The study included 402 patients with mild cognitive impairment, 188 with mild AD (MMSE range 21-26), and 229 with no cognitive impairment. Among the AD patients, 86 were on a ChEI alone, and 73 were on combination therapy. Contrasting with the previously discussed studies, patients in the combination therapy group showed greater decline in the MMSE and Clinical Dementia Rating Scale-Sum of Boxes, which was statistically significant for both.

Side effects reported in cohort studies are presented in table 5. Table 4 summarizes all findings from the cohort studies.

Open-Label Studies

Dantoine et al. [14] conducted a study in 51 centers in France from 2003 to 2005, which enrolled moderate to severe AD patients diagnosed by DSM-IV criteria. In the first part of the study, patients who were not stabilized on treatment with donepezil or galantamine were switched to rivastigmine and monitored. Subsequently, if there was a decline in the MMSE score after 16 weeks, memantine was added to the rivastigmine. No tests of statistical significance were provided by the authors; however, their results suggest improvement in the domains of cognition, behavior, and functional outcome with combination therapy.

In the study by Shua-Haim et al. [26], 16 AD patients diagnosed by NINCDS-ADRDA and DSM-IV, who were community dwelling and had $\mathrm{AD}$ of mild to moderate severity, were 
studied in a single center cross-over study in the US. The primary objective of the trial was to assess steady state pharmacokinetics of the combination therapy, and the secondary outcome was safety and tolerability. The authors concluded that the combination was well tolerated.

A single-arm, open-label pilot study conducted at 20 centers in the US by Olin et al. [25] also had as a main goal to look at tolerability of combination therapy. Included were patients with moderate AD according to NINCDS-ADRDA and DSM-IV who had an MMSE range of 10-20. The intended duration of the study was 26 weeks and 117 patients were included. Patients were given rivastigmine first and memantine was added after 2 weeks. Tests of statistical significance were also not performed. It was concluded that combination therapy is tolerable and safe, and associated with modest changes in cognitive and functional outcome scales.

The study by Riepe et al. [24] was an open-label pilot study conducted at 20 centers in Germany from 2003 to 2004 that included 95 patients with mild to moderate AD diagnosed according to DSM-IV and a MMSE score between 10 and 20. The main goal was to administer neuropsychological tests to patients on combination therapy with rivastigmine and memantine to determine if there was any domain-specific improvement in cognition. Patients had to be on a stable rivastigmine dose for at least 2 weeks prior to the addition of memantine and were on combination therapy for a mean \pm SD of $79.2 \pm 16.7$ days. Statistically significant improvement was found in the memory subscore of the ADAS-cog, attention and orientation components of the MMSE, verbal fluency tests, and forward digit spans. The authors made the observation that patients on the more impaired end of the spectrum of patients were those who had a more pronounced benefit. Tolerability was reported in an earlier companion study [46] in the same population by the same group of authors and is indicated in table 5.

Farlow et al. [22] published a post hoc analysis of a randomized parallel-group, openlabel trial comparing the use of a rivastigmine patch alone with the combination of rivastigmine patch and memantine in patients with mild to moderate AD diagnosed according to NINCDS-ADRDA and DSM-IV. Patients were initially in a 5-week study, which compared the tolerability of an immediate switch with a gradual switching process of oral donepezil to a rivastigmine patch. Patients were then offered to continue in a 20 -week extension phase that was stratified by concomitant memantine use. During the extension phase, there were 118 patients on monotherapy (135 in the initial phase), and 122 on combination therapy (126 in the initial phase). The study determined that the combination is relatively safe, with a slightly worse side effect profile in the combination group that was not statistically significant; however, there was no significant benefit obtained. The Novartis Pharmaceuticals Corporation was involved in sponsorship and authorship of the study.

Lastly, the study by Choi et al. [23] was an open-label parallel-study multi-center trial conducted in South Korea that only enrolled AD patients that met a probable diagnosis by NINCDS-ADRDA criteria. The patients initially went through a run-in period of 8 weeks where a rivastigmine patch was started as monotherapy. All the patients needed to have a Korean MMSE range from 10 to 20 in order to be included in the study. Afterwards, patients were randomized by a computer to either receive memantine or not in addition to the rivastigmine patch, with no blinding for 16 weeks. The LOCF analysis was used, and the significance in differences found at the end of the study did not differ from the OC analysis. A statistically significant difference was found between the control and experimental groups on the Korean version of the Cohen Mansfield Agitation Inventory. There were dropouts from the study during the run-in period before the initiation of memantine. Baseline characteristics were similar, however. The combination was also considered tolerable. 
Muayqil et al.: Systematic Review and Meta-Analysis of Combination Therapy with

Cholinesterase Inhibitors and Memantine in Alzheimer's Disease and Other Dementias

\section{Acknowledgement}

The authors would like to acknowledge Donna Dryden and Ben Vandermeer for their methodological and statistical guidance in conducting the systematic review and meta-analysis.

\section{Disclosure Statement}

The authors have no conflicts of interest to disclose.

\section{References}

1 The Alzheimer Society: Rising Tide: The Impact of Dementia on Canadian Society. 2009.

$\checkmark 2$ Wimo A, Winblad B: Economic aspects on drug therapy of dementia. Curr Pharm Des 2004;10: 295-301.

-3 Wimo A, Winblad B, Jonsson L: An estimate of the total worldwide societal costs of dementia in 2005. Alzheimers Dement 2007;3:81-91.

4 Wimo A, Winblad B, Jonsson L: The worldwide societal costs of dementia: estimates for 2009. Alzheimers Dement 2010;6:98-103.

-5 Barca ML, Engedal K, Laks J, Selbaek G: Quality of life among elderly patients with dementia in institutions. Dement Geriatr Cogn Disord 2011;31:435-442.

-6 Courtney C, Farrell D, Gray R, Hills R, Lynch L, Sellwood E, Edwards S, Hardyman W, Raftery J, Crome P, Lendon C, Shaw H, Bentham P, AD2000 Collaborative Group: Long-term donepezil treatment in 565 patients with Alzheimer's disease (AD2000): randomised double-blind trial. Lancet 2004;363:2105-2115.

7 Sevilla C, Jimenez Caballero PE, Alfonso V, Gonzalez-Adalid M: Current treatments of Alzheimer disease: are main caregivers satisfied with the drug treatments received by their patients? Dement Geriatr Cogn Disord 2009;28:196-205.

-8 Wilkinson D, Schindler R, Schwam E, Waldemar G, Jones RW, Gauthier S, Lopez OL, Cummings J, $\mathrm{Xu} \mathrm{Y}$, Feldman $\mathrm{HH}$ : Effectiveness of donepezil in reducing clinical worsening in patients with mildto-moderate Alzheimer's disease. Dement Geriatr Cogn Disord 2009;28:244-251.

-9 Jain KK: Evaluation of memantine for neuroprotection in dementia. Expert Opin Investig Drugs 2000;9:1397-1406.

-10 Grossberg GT, Pejovic V, Miller ML, Graham SM: Memantine therapy of behavioral symptoms in community-dwelling patients with moderate to severe Alzheimer's disease. Dement Geriatr Cogn Disord 2009;27:164-172.

-11 Wilkinson D, Andersen HF: Analysis of the effect of memantine in reducing the worsening of clinical symptoms in patients with moderate to severe Alzheimer's disease. Dement Geriatr Cogn Disord 2007;24:138-145.

-12 Atri A, Shaughnessy LW, Locascio JJ, Growdon JH: Long-term course and effectiveness of combination therapy in Alzheimer disease. Alzheimer Dis Assoc Disord 2008;22:209-221.

-13 Tariot PN, Farlow MR, Grossberg GT, Graham SM, McDonald S, Gergel I, Memantine Study Group: Memantine treatment in patients with moderate to severe Alzheimer disease already receiving donepezil: a randomized controlled trial. JAMA 2004;291:317-324.

-14 Dantoine T, Auriacombe S, Sarazin M, Becker H, Pere JJ, Bourdeix I: Rivastigmine monotherapy and combination therapy with memantine in patients with moderately severe Alzheimer's disease who failed to benefit from previous cholinesterase inhibitor treatment. Int J Clin Pract 2006;60:110-118.

-15 Xiong G, Doraiswamy PM: Combination drug therapy for Alzheimer's disease: what is evidencebased, and what is not? Geriatrics 2005;60:22-26.

-16 Larsson V, Engedal K, Aarsland D, Wattmo C, Minthon L, Londos E: Quality of life and the effect of memantine in dementia with lewy bodies and Parkinson's disease dementia. Dement Geriatr Cogn Disord 2011;32:227-234. 
Muayqil et al.: Systematic Review and Meta-Analysis of Combination Therapy with

Cholinesterase Inhibitors and Memantine in Alzheimer's Disease and Other Dementias

-17 Weycker D, Taneja C, Edelsberg J, Erder MH, Schmitt FA, Setyawan J, Oster G: Cost-effectiveness of memantine in moderate-to-severe Alzheimer's disease patients receiving donepezil. Curr Med Res Opin 2007;23:1187-1197.

18 Higgins JPT, Green S (eds): Cochrane Handbook for Systematic Reviews of Interventions. Version 5.0.2 [updated September 2009]. The Cochrane Collaboration, 2009.

19 Wells GA, Shea B, O'Connell D, Peterson J, Welch V, Losos M, Tugwell P: The Newcastle-Ottawa Scale (NOS) for assessing the quality of nonrandomised studies in meta-analyses. Department of Epidemiology and Community Medicine, University of Ottawa, Canada. http://www.ohri.ca/programs/clinical_epidemiology/oxford.asp (accessed November, 2011).

-20 Porsteinsson AP, Grossberg GT, Mintzer J, Olin JT, Memantine MEM-MD-12 Study Group: Memantine treatment in patients with mild to moderate Alzheimer's disease already receiving a cholinesterase inhibitor: a randomized, double-blind, placebo-controlled trial. Curr Alzheimer Res 2008;5:8389.

-21 Howard R, McShane R, Lindesay J, Ritchie C, Baldwin A, Barber R, Burns A, Dening T, Findlay D, Holmes C, Hughes A, Jacoby R, Jones R, Jones R, McKeith I, Macharouthu A, O’Brien J, Passmore P, Sheehan B, Juszczak E, Katona C, Hills R, Knapp M, Ballard C, Brown R, Banerjee S, Onions C, Griffin M, Adams J, Gray R, Johnson T, Bentham P, Phillips P: Donepezil and memantine for moderateto-severe Alzheimer's disease. N Engl J Med 2012;366:893-903.

-22 Farlow MR, Alva G, Meng X, Olin JT: A 25-week, open-label trial investigating rivastigmine transdermal patches with concomitant memantine in mild-to-moderate Alzheimer's disease: a post hoc analysis. Curr Med Res Opin 2010;26:263-269.

-23 Choi SH, Park KW, Na DL, Han HJ, Kim EJ, Shim YS, Lee JH, Expect Study Group: Tolerability and efficacy of memantine add-on therapy to rivastigmine transdermal patches in mild to moderate Alzheimer's disease: a multicenter, randomized, open-label, parallel-group study. Curr Med Res Opin 2011;27:1375-1383.

-24 Riepe MW, Adler G, Ibach B, Weinkauf B, Tracik F, Gunay I. Domain-specific improvement of cognition on memantine in patients with Alzheimer's disease treated with rivastigmine. Dement Geriatr Cogn Disord 2007;23:301-306.

-25 Olin JT, Bhatnagar V, Reyes P, Koumaras B, Meng X, Brannan S: Safety and tolerability of rivastigmine capsule with memantine in patients with probable Alzheimer's disease: a 26-week, open-label, prospective trial (Study ENA713B US32). Int J Geriatr Psychiatry 2010;25:419-426.

-26 Shua-Haim J, Smith J, Picard F, Sedek G, Athalye S, Pommier F, Lefevre G: Steady-state pharmacokinetics of rivastigmine in patients with mild to moderate Alzheimer's disease not affected by coadministration of memantine: an open-label, crossover, single-centre study. Clin Drug Investig 2008; 28:361-374.

-27 Schneider LS, Insel PS, Weiner MW, Alzheimer's Disease Neuroimaging I: Treatment with cholinesterase inhibitors and memantine of patients in the Alzheimer's Disease Neuroimaging Initiative. Arch Neurol 2011;68:58-66.

-28 Lopez OL, Becker JT, Wahed AS, Saxton J, Sweet RA, Wolk DA, Klunk W, Dekosky ST: Long-term effects of the concomitant use of memantine with cholinesterase inhibition in Alzheimer disease. J Neurol Neurosurg Psychiatry 2009;80:600-607.

-29 Hartmann S, Mobius HJ: Tolerability of memantine in combination with cholinesterase inhibitors in dementia therapy. Int Clin Psychopharmacol 2003;18:81-85.

- 30 Howard R, Phillips P, Johnson T, O’Brien J, Sheehan B, Lindesay J, Bentham P, Burns A, Ballard C, Holmes C, McKeith I, Barber R, Dening T, Ritchie C, Jones R, Baldwin A, Passmore P, Findlay D, Hughes A, Macharouthu A, Banerjee S, Jones R, Knapp M, Brown RG, Jacoby R, Adams J, Griffin M, Gray R: Determining the minimum clinically important differences for outcomes in the DOMINO trial. Int J Geriatr Psychiatry 2011;26:812-817.

- 31 Schmitt FA, Wichems CH: A systematic review of assessment and treatment of moderate to severe Alzheimer's disease. Prim Care Companion J Clin Psychiatry 2006;8:158-159.

-32 Winblad B, Jones RW, Wirth Y, Stoffler A, Mobius HJ: Memantine in moderate to severe Alzheimer's disease: a meta-analysis of randomised clinical trials. Dement Geriatr Cogn Disord 2007;24:20-27.

- 33 Robert P, Ferris S, Gauthier S, Ihl R, Winblad B, Tennigkeit F: Review of Alzheimer's disease scales: is there a need for a new multi-domain scale for therapy evaluation in medical practice? Alzheimers Res Ther 2010;2:24. 
34 Herndon R: Handbook of Neurologic Rating Scales. New York, Demos Medical Publishing, 2006.

-35 Quinn J, Moore M, Benson DF, Clark CM, Doody R, Jagust W, Knopman D, Kaye JA: A videotaped CIBIC for dementia patients: validity and reliability in a simulated clinical trial. Neurology 2002;58: $433-437$.

-36 Joffres C, Bucks RS, Haworth J, Wilcock GK, Rockwood K: Patterns of clinically detectable treatment effects with galantamine: a qualitative analysis. Dement Geriatr Cogn Disord 2003;15:26-33.

-37 Connor DJ, Sabbagh MN, Cummings JL: Comment on administration and scoring of the Neuropsychiatric Inventory in clinical trials. Alzheimers Dement 2008;4:390-394.

- 38 DiMatteo MR, Giordani PJ, Lepper HS, Croghan TW: Patient adherence and medical treatment outcomes: a meta-analysis. Med Care 2002;40:794-811.

-39 Molnar FJ, Hutton B, Fergusson D: Does analysis using 'last observation carried forward' introduce bias in dementia research? CMAJ 2008;179:751-753.

-40 Molnar FJ, Man-Son-Hing M, Fergusson D: Systematic review of measures of clinical significance employed in randomized controlled trials of drugs for dementia. J Am Geriatr Soc 2009;57:536-546.

-41 Jaeschke R, Singer J, Guyatt GH: Measurement of health status. Ascertaining the minimal clinically important difference. Control Clin Trials 1989;10:407-415.

-42 Burback D, Molnar FJ, St John P, Man-Son-Hing M: Key methodological features of randomized controlled trials of Alzheimer's disease therapy. Minimal clinically important difference, sample size and trial duration. Dement Geriatr Cogn Disord 1999;10:534-540.

-43 Kaduszkiewicz H, Zimmermann T, Beck-Bornholdt HP, van den Bussche H: Cholinesterase inhibitors for patients with Alzheimer's disease: systematic review of randomised clinical trials. BMJ 2005; 331:321-327.

44 Food and Drug Administration: Peripheral and Central Nervous System Drugs Advisory Committee Meeting. Rockville, MD, Department of Health and Human Services, Public Health Service, 1989, p 227.

-45 Hamer RM, Simpson PM: Last observation carried forward versus mixed models in the analysis of psychiatric clinical trials. Am J Psychiatry 2009;166:639-641.

- 46 Riepe MW, Adler G, Ibach B, Weinkauf B, Gunay I, Tracik F: Adding memantine to rivastigmine therapy in patients with mild-to-moderate Alzheimer's disease: results of a 12-week, open-label pilot study. Prim Care Companion J Clin Psychiatry 2006;8:258-263. 